San Jose State University

SJSU ScholarWorks

Master's Theses

Master's Theses and Graduate Research

Fall 2020

\title{
Mobile Ka-Band Polarimetric Doppler Radar Observations Of Wildfire Smoke Plumes
}

Taylor Brianna Aydell

San Jose State University

Follow this and additional works at: https://scholarworks.sjsu.edu/etd_theses

\section{Recommended Citation}

Aydell, Taylor Brianna, "Mobile Ka-Band Polarimetric Doppler Radar Observations Of Wildfire Smoke Plumes" (2020). Master's Theses. 5136.

DOI: https://doi.org/10.31979/etd.x3z5-efze

https://scholarworks.sjsu.edu/etd_theses/5136

This Thesis is brought to you for free and open access by the Master's Theses and Graduate Research at SJSU ScholarWorks. It has been accepted for inclusion in Master's Theses by an authorized administrator of SJSU ScholarWorks. For more information, please contact scholarworks@sjsu.edu. 


\title{
MOBILE KA-BAND POLARIMETRIC DOPPLER RADAR OBSERVATIONS OF
} WILDFIRE SMOKE PLUMES

\author{
A Thesis \\ Presented to \\ The Faculty of the Department of Meteorology and Climate Science \\ San José State University
}

\author{
In Partial Fulfillment \\ of the Requirements for the Degree \\ Master of Science
}

by

Taylor Aydell

December 2020 
(C) 2020

Taylor Aydell

ALL RIGHTS RESERVED 
The Designated Thesis Committee Approves the Thesis Titled

\title{
MOBILE KA-BAND SCANNING POLARIMETRIC DOPPLER RADAR OBSERVATIONS OF WILDFIRE SMOKE PLUMES
}

by

Taylor Aydell

\begin{abstract}
APPROVED FOR THE DEPARTMENT OF METEOROLOGY AND CLIMATE SCIENCE
\end{abstract}

\section{SAN JOSÉ STATE UNIVERSITY}

December 2020

Craig B. Clements, Ph.D.

Department of Meteorology and Climate Science

Minghui Daio, Ph.D. Department of Meteorology and Climate Science

Nicholas McCarthy, Ph.D. $\quad$ Country Fire Authority (CFA) 


\title{
ABSTRACT \\ MOBILE KA-BAND SCANNING POLARIMETRIC DOPPLER RADAR OBSERVATIONS OF WILDFIRE SMOKE PLUMES
}

\author{
by Taylor Aydell
}

Remote sensing techniques have been more recently used to study and track wildfire smoke plume structure and evolution; however, knowledge gaps remain due to the limited availability of observational datasets aimed at understanding the fine-scale fireatmosphere interactions and plume microphysics. In this study, we present a new mobile millimeter-wave (Ka-band) Doppler radar system acquired to sample the fine-scale kinematics and microphysical properties of active wildfire smoke plumes from both wildfires and large prescribed fires. Four field deployments were conducted in the fall of 2019 during two wildfires in California and one prescribed burn in Utah. An additional dataset of precipitation observations was obtained prior to the wildfire deployments to compare the Ka-band specific signatures of precipitation and wildfire smoke plumes. Radar parameters investigated in this study include reflectivity, radial velocity, Doppler spectrum width, Differential Reflectivity $\left(Z_{D R}\right)$, and copolarized correlation coefficients $\left(\rho_{H V}\right)$. Observed radar reflectivity ranged between -15 and $20 \mathrm{dBZ}$ in plume and radial velocity ranged 0 to $16 \mathrm{~m} \mathrm{~s}^{-1}$. Dual-polarimetric observations revealed that scattering sources within wildfire plumes are primarily nonspherical and oblate shaped targets as indicated by ZDR values measuring above 0 and $\rho_{H V}$ values below 0.8 within the plume. Doppler spectrum width maxima were located near the updraft core location and were associated with radar reflectivity maxima. 


\section{ACKNOWLEDGMENTS}

First and foremost, I would like to express my deepest appreciation to my graduate advisor, Dr. Craig Clements, for his continuous support and guidance throughout my graduate career. The completion of my master's thesis would not have been possible without the support of my thesis committee and the insight thy provided throughout the thesis-writing process. Additionally, I would like to thank Matthew Brewer, Scott Purdy, Jackson Yip, and Drs. Nicholas McCarthy, Jean-Baptiste Filippi, and Neil Lareau for their help during field deployments. Lastly, I would like to thank my family and friends in Louisiana for their emotional support the past two years despite the distance between us. Finally, this research was funded by the National Science Foundation's Physical and Dynamic Meteorology Program under Awards AGS-1727052 and AGS-1807774 and the U.S. Forest Service Pacific Northwest Research Station under contracts 19-CR11261987-062 and 18-CR-11261987-085. 


\section{TABLE OF CONTENTS}

List of Tables................................................................. vii

List of Figures.......................................................... viii

1. Introduction......................................................

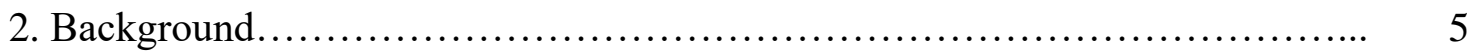

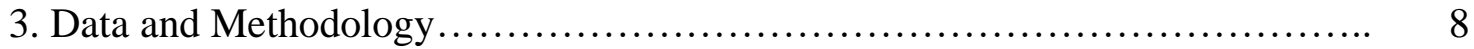

a. Radar Specifications................................................... 8

b. Deployment Rationale................................................... 9

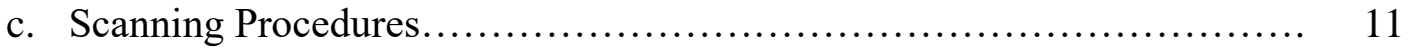

d. Noise and Clutter.................................................. 12

4. Kincade Wildfire Observations............................................... 14

a. D1 Reflectivity analysis......................................... 14

b. D1 Doppler Velocity analysis....................................... 16

c. D1 Analysis of polarimetric variables................................. 18

d. D2 Reflectivity analysis......................................... 21

e. D2 Doppler velocity analysis..................................... 23

f. D2 Spectrum width analysis....................................... 25

5. South Monroe Prescribed Burn Observations................................... 25

a. Reflectivity observations from South Monroe burn....................... 27

b. Velocity observations from South Monroe burn......................... 28

c. Polarimetric observations from South Monroe burn...................... 29

d. Mean variables from South Monroe burn............................... 33

6. Briceburg Wildfire Observations...................................... 36

a. Radar observations from Briceburg Wildfire......................... 36

7. Precipitation Observations............................................ 39

8. Discussion............................................................. 43

9. Conclusions......................................................... 46

10. References....................................................... 47

11. Appendix A............................................................. 55 


\section{LIST OF TABLES}

Table 1. Additional radar specifications and an overview of the output........... 9

Table 2. The specific scanning routines used at each fire will be discussed......... 12 


\section{LIST OF FIGURES}

Figure 1. Figure 1a-c illustrate maps of the total burned area from each of the

wildfires and the location of the radar...

Figure 2. Figure $2 \mathrm{a}-\mathrm{h}$ show radar reflectivity and velocity during the early morning of 24 October 2019

Figure 3. Figure 3a-1 illustrates the differential reflectivity, correlation coefficient, and Doppler spectrum width

Figure 4. Vertical wind profiles taken with the Doppler lidar are shown in Figure 4

Figure 5. PPI scans at an elevation angle $5.04^{\circ}$ were used to measure plume structures and evolution through the collection of radar reflectivity, velocity, and Doppler spectrum width

Figure 6. The CSU-MAPS Doppler lidar was used to obtain vertical wind profiles on the morning of ignition.

Figure 7. The focus of this analysis examines a one-hour period of the smoke plume evolution using an RHI scan procedure

Figure 8. Differential reflectivity, correlation coefficient, and Doppler spectrum width signatures of the South Monroe plume.

Figure 9. Figure 9 shows the mean value of each variable along three different elevation angles for the one-hour period.

Figure 10. Figure 10 a-h illustrates radar reflectivity and velocity observations of the Briceburg wildfire beginning at 13:25 PST....

Figure 11. Fig. 11a-d illustrates an RHI scan that details radar reflectivity, correlation coefficient, differential reflectivity, and Doppler spectrum width of the precipitating cloud deck at 10:50 PST.

Figure 12. Figure 12 a-i illustrates radar reflectivity, radial velocity, and Doppler spectrum width of the precipitating system beginning at 12:50:20 PST. 
Figure 13. A conceptual diagram was created to show an overview of the findings from this study highlighting the dual-polarization

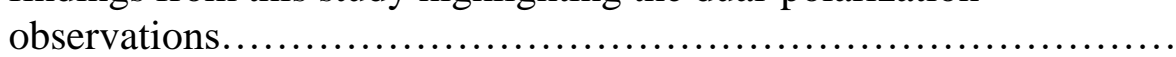




\section{LIST OF ABBREVIATIONS}

FASMEE - Fire and Smoke Model Evaluation Experiment

FFT - fast Fourier transform

KASPR - Ka-band Scanning Polarimetric Radar

NEXRAD WSR 88D - Next Generation Weather Radar program, Weather Surveillance Radar, 1988, Doppler

PPI - Plan Position Indicator

RHI - Range Height Indicator

SW - spectrum width

ZDR - Differential Reflectivity

$\rho h v$ - Copolar Correlation Coefficient 


\section{Introduction}

Wildfires are high-impact societal problems for the western United States and other fire-prone regions that can result in loss of life, property, and natural resources as well as degraded human health through the release of smoke and by-combustion products (Dempsey 2012; McRae et al. 2015; Clements et al. 2018). The number of people choosing to live in high fire danger areas and the urban-wildland interface region further increases the risks wildfires pose to large communities and to firefighters protecting these areas. Wildfire smoke plumes can cause regional- to global-scale impacts through smoke injection into the atmosphere such as reduced solar radiation (Penner et al. 1992; Price et al. 2016), altered aerosol concentrations in the upper and lower atmosphere (Fromm 2006), and unexpected smoke transport (Lareau and Clements 2015). For these reasons, it is highly desirable to understand and predict fire behavior, fire-atmosphere interactions, and smoke production; however, progress is hampered by a lack of wildfire observations.

Wildfire plume dynamics, fire behavior, and the interaction amongst them have been studied and documented through laboratory experiments, but observations of actual wildfire plumes are limited. Several researchers have tried to address various aspects of plume dynamics including the mean and turbulent structures of wildfire convective plumes, the role entrainment and detrainment plays on plume rise (Lareau and Clements 2016, 2017), and the process of deep pyroconvection (Lareau et al. 2018; McRae et al. 2015; Banta et al. 1992). The relationship between plume dynamics and the atmosphere, or fire-atmosphere coupling, has received the most attention within the wildfire research community. This coupling mechanism has been well documented from a theoretical 
perspective and through small, prescribed fires (Clements et al. 2007, 2015, 2019); however, there has been limited investigation into larger wildfires. In large, vigorous wildfires, plume dynamics play a significant role in short- and long-range firebrand transport, further complicating the ability to deterministically model these phenomena (Cruz et al. 2012; McCarthy et al. 2018). Understanding the dynamic processes in wildfires and connecting them to resulting fire behavior is key to developing and validating predictive tools for fire management.

Plume microphysical research has been conducted using various types of remote sensing platforms that require an understanding of the returned backscatter, putting an emphasis on resolving the scattering sources and their relationship to the physical properties of wildfires. Recent progress in understanding wildfire smoke plume microphysics have detailed the larger particles and aerosols that are generated from the combustion processes (Banta et al. 1992; Baum et al. 2015; LaRoche et al. 2017; Jones and Christopher 2009, 2010a, b; McCarthy et al. 2018, 2019), yet no observational studies have aimed to address the characteristics of the particles that reside in the submicron range. The consensus across multiple studies indicates that ash is the dominant scattering source within smoke plumes, revealing the presence of non-spherical and horizontally oriented plume particles (Melnikov et al. 2008, 2009; Lang et al. 2014). Beyond the basic geometry and size distributions of smoke plume particles, knowledge regarding the dynamic components and electromagnetic properties of scatterers is limited (McCarthy et al. 2019). Close range, high resolution datasets are needed to resolve the details of wildfire scattering sources. 
Meteorological sampling of wildfires have been performed at very coarse resolution, limiting the understanding of the fine-scale fire-atmosphere interactions and plume microphysics. Airborne and spaceborne observation techniques have been extensively used to monitor wildfires, smoke dispersion, and air quality primarily through the use of polar orbiting and geostationary satellites and aircraft measurements. Specifically, spaceborne satellites have been proven useful in providing the spatial and vertical distributions of wildfire smoke and debris plumes and their properties (Jones and Christopher 2010). Research aircraft applications have been used in more recent studies to track smoke emissions and plume chemistry (Johnson et al. 2008; Rodriguez 2018). Direct sampling of individual smoke and debris plumes through in situ collection techniques has been limited, creating a lack of quantitative data on plume dynamics. Few studies have utilized ground based remote sensing platforms to study wildfires, yet they provide a way to obtain in situ data while satisfying safety concerns and logistical complications (McCarthy et al. 2019).

When deployed in a safe manner, ground-based active remote sensing, such as meteorological radar and lidar, can address some of the methodological difficulties of observing in the wildland fire environment (McCarthy et al. 2018; Clements et al. 2018). For example, scanning Doppler lidar has been used to resolve the dynamics, kinematics, and turbulent properties of wildfires through analysis of lidar backscatter intensity and radial velocity estimates (Banta et al. 1992; Charland and Clements 2013; Lareau and Clements 2016; 2017; Clements et al. 2018). Limitations of using lidar include range 
(typically $<10 \mathrm{~km}$ ) and attenuation in moist convection and optically thick plumes with high ash density.

While lidar has been used to study wildfire plumes, meteorological radar has been used less for wildfire research, with applications primarily in a supplemental capacity (McCarthy et al. 2019). Meteorological radars are capable of employing a range of microwave frequencies to obtain high-resolution, near real-time data without compromising the safety of those conducting the research. One of the first pioneering studies utilizing radar for studying wildfires and plume characteristics was that of Banta et al. 1992, in which an X-band Doppler radar and Doppler lidar were used to investigate the internal and external environment of a forest fire plume. Recent investigations into wildfire smoke plume microphysics have focused on the dual polarimetric radar signatures through the analysis of radar equivalent reflectivity factor, radial velocity, and correlation coefficient of large ash and pyrogenic particles (Jones and Christopher 2009, 2010; McCarthy et al. 2018; 2019). To date, the consensus among studies that used polarimetric radars is that the primary scattering material is dominantly ash, however many questions remain regarding the scattering material of wildfire origin (Jones and Christopher 2009, 2010; Melnikov et al. 2008; McCarthy et al. 2018). The most common types of radar used for these studies have utilized data from the operational dualpolarization radars, such as the NEXRAD WSR-88D network. The wavelength of operational radars $(\sim 10 \mathrm{~cm})$ allows for the detection of large, ash particles but limits the observations of small-scale processes within the plume and microphysical properties. Motivated by the need for more detailed wildfire plume sampling, a mobile truck- 
mounted, millimeter wavelength radar was used to examine the microphysical regimes of wildfire smoke plumes.

Millimeter wavelength radars are ideally suited to study clouds, small hydrometeors in precipitating systems, and ash lofted by wildfires. In this study, we present a new mobile millimeter-wave (Ka-band) Doppler radar system to sample the fine-scale kinematics and microphysical properties of active wildfire smoke plumes from both wildfires and prescribed fires. This work demonstrates the advantages of utilizing a portable, millimeter wavelength radar for monitoring and advancing the understanding of wildfire plume dynamics using close range observations from the fire environment.

\section{Background}

Studying pyrometeor targets is difficult due to the complex nature of wildfires and the highly irregular scattering materials within the plume (McCarthy et al. 2019). It is known that the interaction between electromagnetic waves and radar targets depends on the frequency of the radiation and on the size, shape, composition, and distribution of the material within the beam (Rauber and Nesbitt 2018); however little is known regarding these properties of wildfire by-products. There are many considerations when studying wildfire scatterers and pyrometeors using meteorological radars. The basis of studying pyrometeors from particle scattering is based on the Rayleigh and Mie Scattering theories of Mie's solution to Maxwell's equations for the interaction of radiation with a sphere (Rauber and Nesbitt 2018). Under these theories, radar equivalent reflectivity produced from particle-based scattering is dependent on the wavelength of the radar, the radar cross section per unit volume, and the dielectric constant, $K$. The radar cross section (RCS, i.e., 
$\sigma$ ) equation (Eq. 1) relates these parameters of the radar system to an ensemble of spherical raindrops with diameters $(D)$,

$$
\sigma=\frac{\pi^{5}|K|^{2} D^{6}}{\lambda^{4}}
$$

where the radar wavelength $(\lambda)$ and dielectric constant $(K)$ are assumed to be essentially constant across all weather radar applications. However, the target's radar cross section is dependent on the geometric, electromagnetic, and dynamical properties of the targets within the radar's beam path (Baum et al. 2015). This underlying equation of all meteorological radars is based on the critical assumptions that all targets within the radar beam consist entirely of dielectric spheres and that the particles are much smaller than the wavelength of the radar (Rayleigh scattering theory). A third critical assumption is that the reflectivity returned is the water-equivalent reflectivity, or that the dielectric constant, $K$, is 0.93 . Therefore, in the context of hydrometeors, these factors are known for a wide range of meteorological phenomena. There have been studies to find a dielectric constant more suited for studying pyrometeors (Adams et al. 1996); however, the derived value of $K$ has not been used to analyze radar reflectivity from wildfires and would not be comparable to any literature.

Geometric properties, those that detail the shape, surface area, and aspect ratio, affect how much energy is returned to the radar. These properties within wildfire plumes have been extensively studied in the past. Findings indicate that the primary source of scatterers within plumes are ash particles and are considered to primarily be seen as needlelike by the radar (Banta et al. 1992; Melnikov et. al. 2009; Baum et. al. 2015). The 
electromagnetic properties, which are a function of the molecular composition, mass, and temperature, have primarily been studied using laboratory settings and a theoretical framework. Baum et al. (2015) analyzed the electromagnetic material properties of ash particles through the analysis of their complex permittivity. The dynamical properties of radar targets have received the least attention of the three properties, with limited studies investigating these properties. The work of Baum et al. (2015) considered ash to have two modes of dynamic behavior during descent, concluding that radars effectively see pyrometeor targets as horizontally oriented, needle-like structures. Limited understanding of the RCS of these pyrometeor targets has constrained the interpretation of wildfire radar signatures, representing a significant gap in wildfire research.

$$
Z=\frac{\Sigma_{j} D_{j}^{6}}{V_{c}}
$$

Progress in understanding wildfire by-products has been further hampered by a lack of in situ observations of particle size distribution. Detailing the particle size distribution is needed to infer how different scatterers affect radar scattering, as the radar reflectivity factor, $Z$, is heavily dependent on the diameter $(D)$ of the targets (Eq. 2). Few in situ observations of wildfire scatterers have been conducted through field studies detailing biomass burning emissions. Reid et al. (2005) examined biomass burning emissions physical, chemical, and optical properties and found that $\sim 10 \%$ of wildfire emissions lie in the diameter range of 2 to $20 \mu \mathrm{m}$, while giant ash particles produced from large, intense wildfires can have diameters of up to a millimeter or more (Reid et al. 2005). While considerable research has been conducted to detail the size and geometric 
properties of large debris and firebrands (Koo et al. 2010), no studies have aimed to detail the full distribution of particle sizes from wildfire plumes (McCarthy et al. 2019). Particles from wildfire origin have a wide range of shape and sizes, therefore in situ observations are needed to form a solid foundation for wildfire scattering theory.

\section{Data and Methodology}

\section{a. Radar Specifications}

The Ka-band Scanning Polarimetric Radar (KASPR) was manufactured by Prosensing, Inc., and acquired by San José State University to sample fine-scale fire-atmosphere interactions within ash and debris plumes of wildfires. KASPR is a fully-scanning, dualpolarimetric millimeter wavelength radar suited for studying clouds, small hydrometeors, and ash lofted by wildfires. KASPR operates at $35.61 \mathrm{GHz}$ with a solid-state power amplifier that has a peak power of $10 \mathrm{~W}$ and an antenna with a diameter of $1.8 \mathrm{~m}$. This unit is comprised of a radar transmitter, antenna, elevation and azimuth scanning pedestal, control software, digital receiver, and an electronics enclosure. The radar pedestal is mounted to a flatbed deck on a Ford F-250 4x4 pickup truck (Fig. 1d). An automatic leveling system (Bigfoot Leveling Systems, AC-12K24) levels the truck and radar in under 3 minutes once the truck on site. This hydraulic leveling system provides 24 " throw and has a 12,000 lb load capacity per jack providing a safe and stable platform for deployments.

The software of the radar system provides various data processing functions, including pulse compression, clutter filtering, continuously updated noise estimation, FFT processing, and calibrated dBZ computation. For real-time monitoring of the output data, KASPR has a display client that can be operated from the unit or remotely from any 
location. For operations, the radar specifications are well suited for deployments that observe targets within $15 \mathrm{~km}$ of the radar unit. Range resolutions for the system vary from 7.5 to $120 \mathrm{~m}$, however it is primarily operated at the 15 and $30-\mathrm{m}$ range resolution for our plume observations. Additional radar specifications and an overview of the output parameters used in this study are summarized in Table 1.

TABLE 1. KASPR specifications and operating characteristics.

\begin{tabular}{|c|c|}
\hline Parameter & Specification \\
\hline Frequency & $35.68 \mathrm{GHz}$ (wavelength $8.4 \mathrm{~mm}$ ) \\
\hline Transmitter Power & $10 \mathrm{~W}$ peak SSPA, $25 \%$ duty cycle max \\
\hline Antenna Diameter & $1.82 \mathrm{~m}$ \\
\hline \multirow[t]{2}{*}{ Antenna Polarization } & Tx: Alternate $\mathrm{H} / \mathrm{V}$ polarization \\
\hline & Rx: Simultaneous V/H pol \\
\hline Beamwidth & $0.31^{\circ}$ \\
\hline LNA Noise Figure & $2.8 \mathrm{~dB}$ \\
\hline Range Resolution & $7.5,15,30,60,120 \mathrm{~m}$ \\
\hline Max Scan Rate & $20^{\circ}$ per second \\
\hline \multirow[t]{3}{*}{ Radar Data Products } & $\mathrm{dBZ}_{\mathrm{V}}, \mathrm{dBZ}_{\mathrm{H}}, \mathrm{L}_{\mathrm{DR}}, \mathrm{Z}_{\mathrm{DR}}, \rho \mathrm{hv}, \phi_{\mathrm{DP}}$ \\
\hline & $\begin{array}{l}\text { power spectra: VV, HH, HV, HH; velocity and spectral } \\
\text { width. }\end{array}$ \\
\hline & Dual PRI velocity for alias unwrapping \\
\hline
\end{tabular}

\section{b. Deployment Rationale}

The design of our deployable radar unit allows for rapid deployments to fires using the "storm chaser" approach that is widely used in the severe weather community (Bluestein 1999). Our deployment strategy requires all team members to be fireline qualified to ensure the safety of all research members and equipment during operations (Clements et al. 2018). Communication with key fire personnel and fire management 
agencies was maintained during all operations at wildfires and prescribed fires. Deployment site decisions are largely influenced by the local terrain attributes and ambient meteorological conditions. Sites were chosen based on accessibility and safety while remaining at a distance that satisfies our research objectives.

Four field deployments were conducted in the fall of 2019 during two wildfires in California and one prescribed burn in Utah. Figures (1a-c) illustrate maps of the total burned area from each of the wildfires and the location of the radar. The Briceburg fire in Mariposa County, California began on 6 October 2019 and was the first wildfire to which we deployed the radar unit (Fig. 1c). The second and third deployment were to the Kincade wildfire in Sonoma County, California which was active from 9 - 24 October 2019 (Fig.1a). Lastly, we collected data on a large, prescribed crown fire (a high-intensity fire burning the forest canopy) as part of a multi-agency field campaign in Fishlake National Forest, Utah on 7 November 2019 (Fig. 1b). Except for the Briceburg wildfire, all observations were made from $5 \mathrm{~km}$ of the active fire front. Briceburg observations were taken from $12 \mathrm{~km}$ upwind; therefore, the resolution of this dataset is lower than the others. Two additional datasets of precipitating cloud decks were obtained on 18 September 2019 and 06 April 2020 in California near San José State University and will also be analyzed in this study. Appendix A includes additional photos taken at each wildfire deployment. 

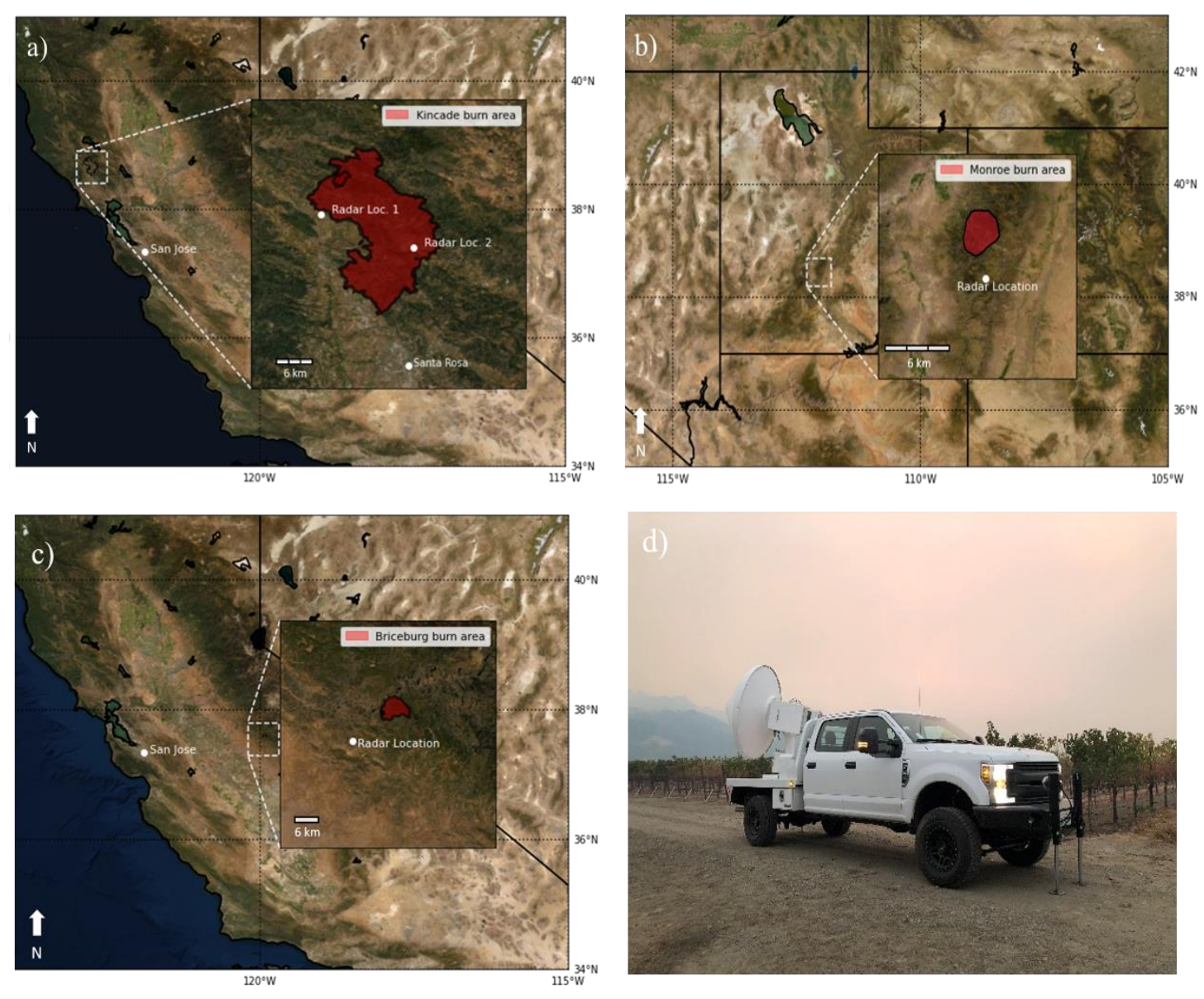

Figure 1. Maps of deployments to the (a) Kincade, (b) South Monroe, and (c)

Briceburg fires and the location of the radar site. The last image (d) is a photo of the radar unit that was taken on the first deployment on 23 October 2019.

\section{c. Scanning Procedures}

Various scan procedures can be used to study the structure and evolution of debris and ash plumes (Jones and Christopher 2009, 2010; Melnikov et al. 2008; McCarthy et al. 2018). Scan procedures were not decided prior to deployment, but rather on a case-by- 
case basis that depended on the environmental conditions and direction from which the scans were taken. In this study, two types of scanning techniques were used: RangeHeight-Indicator (RHI) and Plan-Position-Indicator (PPI). RHI scans were used to obtain vertical cross-sections through the plume to detail the vertical distribution of various radar variables. Low-elevation PPI scans were performed to collect horizontal cross sections of the near-fire atmosphere. Depending on the fire's location, various azimuth and elevation angles were used to optimize the observations of the plume. The specific scanning routines used at each fire will be discussed in the analyses section and are listed in Table 2.

TABLE 2. Fire and deployment information including radar scan details.

\begin{tabular}{|c|c|c|c|c|c|c|c|c|}
\hline $\begin{array}{c}\text { Fire } \\
\text { Name }\end{array}$ & $\begin{array}{c}\text { Date of } \\
\text { Ignition }\end{array}$ & $\begin{array}{c}\text { Date } \\
\text { Deployed }\end{array}$ & $\begin{array}{c}\text { Lat/Lon } \\
\left({ }^{\circ}\right)\end{array}$ & $\begin{array}{c}\text { Total } \\
\text { Acres } \\
\text { Burned }\end{array}$ & $\begin{array}{c}\text { Radar } \\
\text { Scan } \\
\text { Strategy }\end{array}$ & $\begin{array}{c}\text { Radar } \\
\text { Az. } \\
\text { Angle } \\
\left({ }^{\circ}\right)\end{array}$ & $\begin{array}{c}\text { Corrected } \\
\text { Az. Angle } \\
\left(^{\circ}\right)\end{array}$ & $\begin{array}{c}\text { Elevation } \\
\text { Angle }\left(^{\circ}\right)\end{array}$ \\
\hline Kincade & $\begin{array}{l}23 \text { Oct. } \\
2019\end{array}$ & $\begin{array}{l}23 \text { Oct. } \\
2019, \\
27 \text { Oct. } \\
2019\end{array}$ & $\begin{array}{l}38.972458, \\
- \\
122.780053\end{array}$ & 77,758 & $\begin{array}{l}\text { D1: RHI } \\
\text { D2: PPI }\end{array}$ & $190^{\circ}$ & $35^{\circ}$ & $\begin{array}{l}\text { D1: } 5.0^{\circ}- \\
60.0^{\circ} \\
\text { D2: } 5.04^{\circ}\end{array}$ \\
\hline $\begin{array}{l}\text { South } \\
\text { Monroe }\end{array}$ & $\begin{array}{l}7 \text { Nov. } \\
2019\end{array}$ & $\begin{array}{l}7 \text { Nov. } \\
2019\end{array}$ & $\begin{array}{l}38.26200, \\
-112.02375\end{array}$ & $\sim 800$ & RHI & $152^{\circ}$ & $321^{\circ}$ & $\begin{array}{l}3.0^{\circ}- \\
80.0^{\circ}\end{array}$ \\
\hline Briceburg & $\begin{array}{l}6 \text { Oct. } \\
2019\end{array}$ & $\begin{array}{l}9 \text { Oct. } \\
2019\end{array}$ & $\begin{array}{l}37.604638 \\
-119.96606\end{array}$ & 5,563 & RHI & $82^{\circ}$ & $47^{\circ}$ & $\begin{array}{l}0.05^{\circ}- \\
11.65^{\circ}\end{array}$ \\
\hline
\end{tabular}

\section{d. Noise and Clutter}

Six datasets in total were analyzed in this study, with five types of radar data represented. All data analyses conducted were completed using the open-source PyArt package (Helmus and Collis 2016). Several efforts were made to mitigate ground clutter 
and the effects of noise sources on the output variables. Various gate filter thresholds were used to mitigate these effects through the PyArt package. The first gate filter applied excluded masked and invalid returns to the radar for all variables. Further inspection of the scans revealed a significant amount of clutter around the smoke plume boundaries, therefore additional gate filters were applied to specific parameters where noise artifacts were present. Radial velocity returns with values between -1 and $1 \mathrm{~m} \mathrm{~s}^{-1}$ were excluded from the analysis. The maximum in plume radial velocity was measured at $28.6 \mathrm{~m} \mathrm{~s}^{-1}$, therefore values greater than $\pm 30 \mathrm{~m} \mathrm{~s}^{-1}$ were also excluded. Additionally, the copolar correlation coefficient was also constrained to be within .05 and 1.0. Values outside of this threshold would not be representative of the smoke plume or any meteorological target. With these thresholds in place, a significant reduction in noise was achieved. Lastly, KDP (Specific Differential Phase) calculations were made through the PyArt package following the estimation schemes by Maesaka et al. (2012), Schneebeli et al. (2014), and Vulpiani et al. (2012).

The following analyses will address the characteristics of radar reflectivity, velocity, and the polarimetric variables to detail the radar specific signatures of ash and debris plumes. First, the datasets collected from the Kincade wildfire deployments are examined. These datasets detail the evolution of the plume during a period where both RHI and PPI scans were made. Next, RHI scans made of the vertical plume growth during the South Monroe prescribed burn are examined. Following this analysis, the Briceburg wildfire radar reflectivity and velocity signatures are discussed. Lastly, observations of precipitation are analyzed and compared to the wildfire plume signatures. 


\section{Kincade Wildfire Observations}

The Kincade wildfire ignited on 23 October 2019 at approximately $38.769^{\circ} \mathrm{N}$, $122.767^{\circ} \mathrm{W}$ in Sonoma County, California (CalFire, b). This wildfire was the largest wildfire of 2019 in the United States, caused the evacuation of $\sim 190,000$ people, and burned a total of 77,758 acres (CalFire, b). For comparison, the Camp fire in 2018 burned a total of 153,336 acres and stands as the deadliest wildfire in California's history (CalFire, c). Two deployments were conducted during this wildfire and will be denoted as D1 and D2 hereafter. Deployments were conducted on the first night of ignition, 23 and 24 October, and during a second downslope wind event on 27-28 October. The radar scanned from positions less than $5 \mathrm{~km}$ from the active fire fronts. Scanning procedures used for these observations were chosen after assessing the ambient atmosphere conditions and local terrain features. Two types of scans, RHI and PPI, were used during D1 and D2, respectively.

\section{a. D1 Reflectivity analysis}

KASPR was deployed on the night of 23 October 2019 to Alexander Valley $\left(38.945^{\circ} \mathrm{N}, 122.705^{\circ} \mathrm{W}\right)$ in Sonoma County. At this time, a fire weather watch was in effect for this region with forecasted local gusts exceeding $27 \mathrm{~m} \mathrm{~s}^{-1}$ and poor humidity recoveries in the surrounding mountains in the Sonoma County region. The Kincade wildfire was first reported at 2124 PST during the extreme wind event, rapidly growing to 10,000 acres within the first six hours since ignition (CalFire, b). Observations were conducted through the night of 23 October and into the following morning. 
To examine the radar signatures of the Kincade wildfire plume, we analyzed radar reflectivity factor, Doppler velocity, and dual-polarimetric parameters. Figure 2a-h show radar reflectivity and velocity during the early morning of 24 October. The chosen scanning procedure for this time was an RHI scan that captured the vertical propagation of debris above the active fire front and the dispersion of lofted smoke and ash. Our target elevation angles were $5^{\circ}$ to $160^{\circ}$ at an azimuth angle of $35^{\circ}$ (Table 2). The target scan rate was at $4^{\circ} \mathrm{s}^{-1}$. The smoke plume remained below $3 \mathrm{~km}$ AGL, with few return signals above this level. The active fire front region was located on a ridge; therefore elevation scans below $5^{\circ}$ were not made.

Figure 2a-h illustrates the evolution of radar reflectivity and Doppler velocity during the first night of fire spread. Specifically, these scans detail a 4-minute segment when the smoke plume propagated vertically and advected downwind. Radar reflectivity values ranged from -20 to $15 \mathrm{dBZ}$ in the plume, with the highest returns corresponding to the area above the active fire front located $5.8 \mathrm{~km}$ upwind. During this scan time, ash and debris were observed falling out the plume onto the radar deployment site, resulting in reflectivity returns just above the scan location. Above the radar location, reflectivity returns ranged from -10 to $0 \mathrm{dBZ}$, illustrating smaller particles remained lofted above the surface. In general, the maximum reflectivity values were confined closer to the fire front region, while smaller pyrometeors were advected downwind and eventually fell out. A notable feature within the reflectivity data is the location of weak returns directly underneath the plume base. This region of weak reflectivity measured values between -14 and $-8 \mathrm{dBZ}(\sim 4 \mathrm{~km}$ upwind) and likely 
represent the fallout of small debris and ash particles ahead of the plume as a result of clean air entrainment. With time, this area of weak reflectivity extended vertically and increased in magnitude as the plume grew vertically, indicating increased fallout of the smaller particles.

\section{b. D1 Doppler velocity analysis}

Analysis of Doppler velocities indicated plume particles were traveling 4 to $12 \mathrm{~m} \mathrm{~s}^{-1}$

towards the radar, with some velocities exceeding $15 \mathrm{~m} \mathrm{~s}^{-1}$ (Figure 2e-h). The locations of maximum velocities correspond with the maximum radar reflectivity returns above the base of the plume. Observed radial velocities are greatest near the surface and generally weakened with height likely as a result of the vertical wind structure associated with the downslope windstorm. At approximately $3 \mathrm{~km}$ upwind of the radar location, the scans captured an increase in outbound velocities (red) of magnitude 1- $4 \mathrm{~m} \mathrm{~s}^{-1}$, indicating horizontal acceleration of the wind towards the base of the plume ( $\sim 5 \mathrm{~km}$ upwind). In contrast, an increase of inbound velocities can be seen to be located downwind of the plume base, at approximately $4 \mathrm{~km}$ upwind of the radar. This small location of outbound and inbound velocities indicates the formation of a horizonal convergence zone ahead of the base of the plume. The development of convergence zones downwind of fire fronts have been reported in previous case studies (Clements el al. 2007; Charland and Clements 2013). 

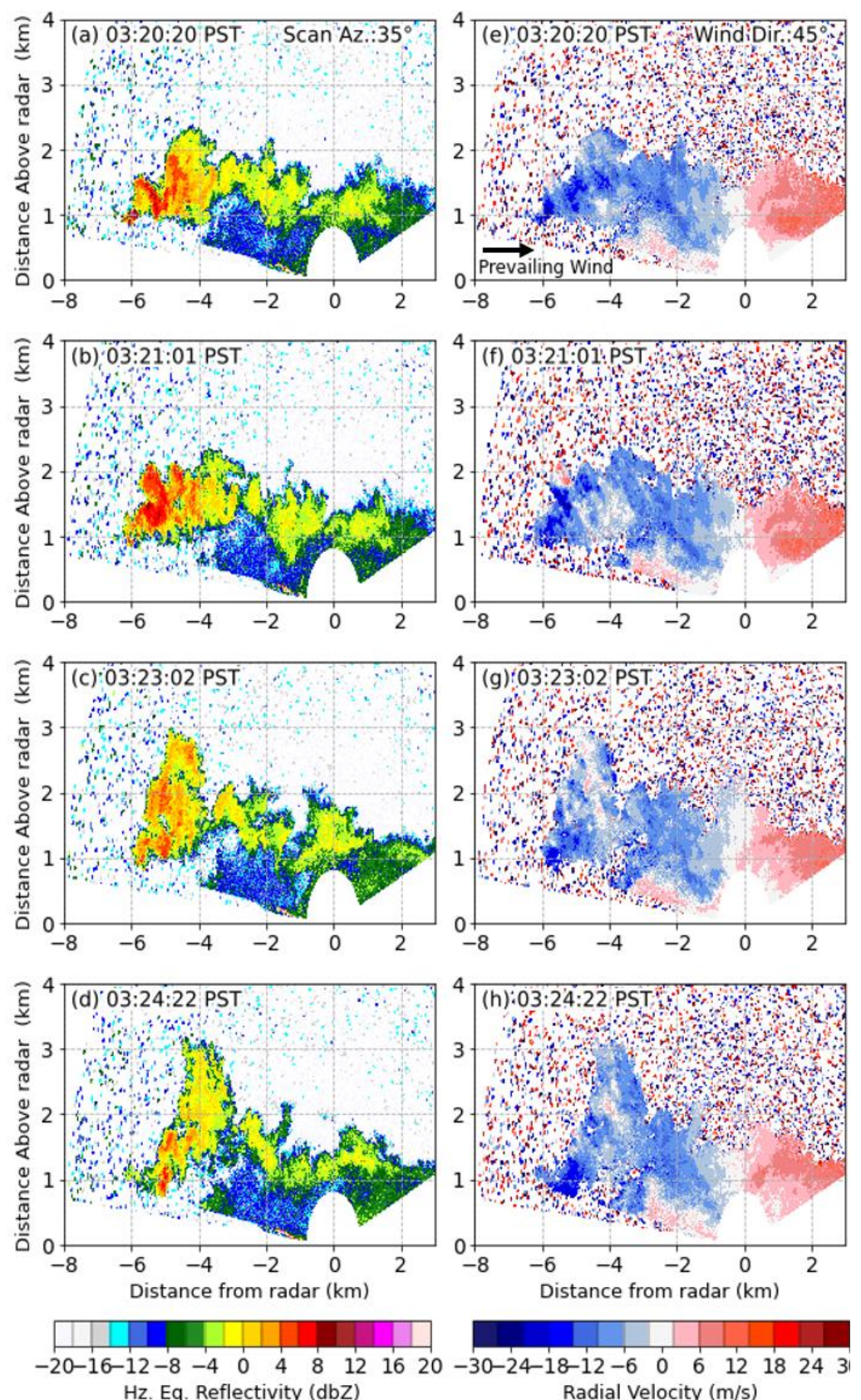

Figure 2. KASPR radar signatures from D1 to the Kincade wildfire on 24 October 2019. Fields are as the following: (a)-(d) horizontal equivalent reflectivity factor $\left(\mathrm{dBZ}_{\mathrm{H}}\right)$ and $(\mathrm{e})$-(h) radial velocity $\left(\mathrm{m} \mathrm{s}^{-1}\right)$ beginning at 3:20 PST. Scans were taken along the same azimuth for all time periods.

Acceleration into the upwind side of the plume base $(\sim 5.5 \mathrm{~km})$, likely fire-induced, is 
observed for all scan times. Increased velocities near the fire front location $(\sim 5.0 \mathrm{~km})$ likely occurred as a result of a decrease in surface pressure induced by the fire.

Underneath this region of increased velocities, an area of clean air is seen to be present in both the reflectivity and velocity data $(\sim 4.0 \mathrm{~km})$. This feature is likely indicative of an inflow jet supplying the fire with clean, debris-free air or represents a leeward rotor-like circulation forming downwind of a ridgeline. Because we were scanning perpendicular to a ridge, the elevation could not be lowered to obtain the kinematic structure directly beneath the plume. Along beam velocities indicate ash and debris were subsiding directly downwind of the radar likely as ashfall. Furthermore, a decrease in radar reflectivity values with altitude also suggests that some of the debris may have moved out of the scan plan of the radar.

\section{c. D1 Analysis of polarimetric variables}

Dual polarimetric observations were collected during the Kincade deployment to detail the microphysical properties of wildfire pyrometeors. Figures 3a-l illustrates the differential reflectivity, correlation coefficient, and Doppler spectrum width for the same period as Fig. 2. Differential reflectivity provides information about the orientation of the scatterers and has been used extensively to detail ash and fire debris lofted from wildfires (Jones and Christopher 2009; McCarthy et al. 2018; Zrnic et al. 2020). As shown in Figs. 3a-d, ZDR returns from this smoke plume are positive and indicate that the targets primarily lie in their horizontal plane. Near the plume base, ZDR values are very inhomogeneous and range from 1 to $6 \mathrm{~dB}$. The locations at which reflectivity returns were the greatest (> $5 \mathrm{dBZ}$ ), differential reflectivity values were low 
(0-1 dB). Low ZDR values in areas with high radar reflectivity are likely caused by

turbulent and fluttering motions. Conversely, regions with lower reflectivity values were collocated with higher differential reflectivity of values 3-5 dB or where the targets lie in their horizontal plane.
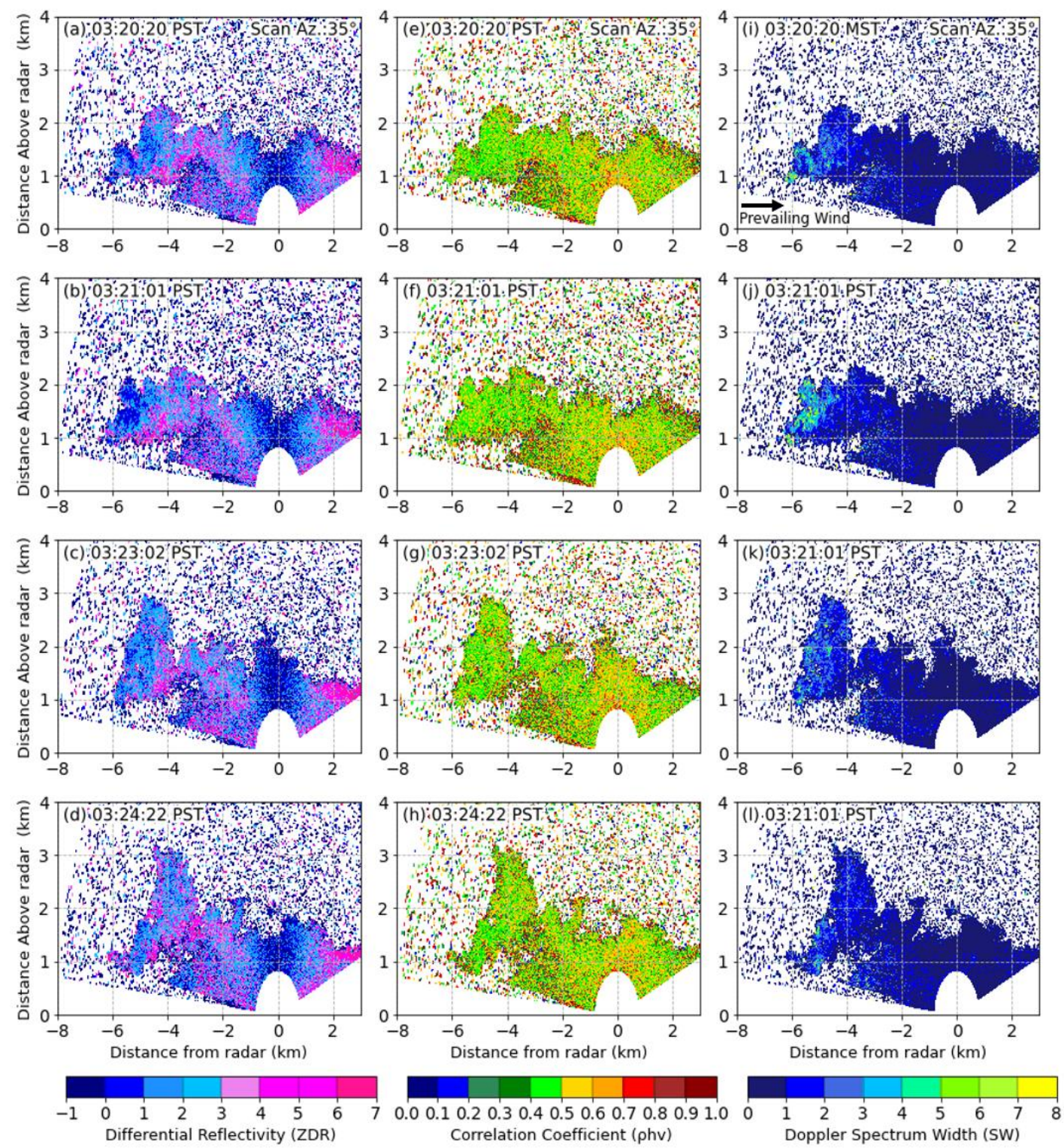

Figure 3. Same RHI scan as Fig. 2 beginning at 3:20 PST on 24 October 2019. The following fields shown are (a)-(d) differential reflectivity $\left(\mathrm{Z}_{\mathrm{DR}}\right)$, (e)-(h) copolar correlation coefficient ( $\rho$ hv), and (i)-(l) Doppler spectrum width. 
Copolar correlation coefficient $(\rho h v)$ is a parameter that details the statistical consistency of the phase measurements in the radar volume (Rauber and Nesbitt 2018). Copolar correlation coefficient values were low closest to the plume base and ranged between 0.3 and 0.5 , indicating that a wide array of particle shape and sizes with random motions were being observed. A slight increase in correlation coefficient with time can be seen above the base of the plume ( $\sim 5 \mathrm{~km}$; Fig. $3 \mathrm{f}, \mathrm{g})$. Directly underneath the plume base, near the clean air region $(\sim 4 \mathrm{~km})$, the correlation coefficient varies between 0.7 and 0.8 revealing a more uniform region of the plume. Furthermore, increased values can also be seen to be located above the radar site in all scans presented. Larger correlation values indicate that the more homogenous particles remain lofted in the plume.

Doppler spectrum width is the measure of the spread of radial motions of scatterers within the pulse volume and is primarily affected by wind shear, turbulence, and variations in particle fall velocities. Spectrum width has received little attention for wildfire studies, yet it is an effective tool for highlighting turbulent flow in wildfire convective plumes. The signature of spectrum width highlights consistently low values within the downwind regions of the plume. Near the updraft zone, where the movement of air is the greatest, regions of higher spectrum width $(\sim 5.8 \mathrm{~km})$ indicate the turbulent structure of the plume core $\left(7 \mathrm{~m} \mathrm{~s}^{-1}\right)$ associated with strong updrafts. Increased spectrum width on the windward side of the plume is also indicative of increased wind shear in this zone. This finding suggests that the updraft cores are the most turbulent region of the plume. 
It is also important to note that areas of increased spectrum width correspond to areas where reflectivity and velocity are the greatest. In regions where subsidence increased and the plume is bent over, Doppler spectrum width decreased drastically. The implication of this is that regions where the plume is vertically extended and the updraft intensity is likely the greatest, an increase in Doppler spectrum width should be observed. Understanding the turbulent structures that govern the transport of fire by-products such as firebrands, is highly desirable for validating the turbulent processes of wildfires.

\section{d. D2 Reflectivity analysis}

KASPR was deployed for a second time to the Kincade wildfire on the evening of 27 October. At this time, a much stronger downslope wind event was forecasted to occur during the evening and persist through the early morning. This wind event presented favorable conditions for rapid fire growth and extreme rate of spread. Because this event was forecasted days in advance, our secondary profiling truck was also deployed. The California State University--Mobile Atmosphere Profiling System (CSU-MAPS) is equipped with a scanning Doppler lidar and a surface weather station (Clements and Oliphant 2014). These data will not be discussed in detail for this analysis, however vertical wind profiles are shown to provide the ambient wind conditions at the time of KASPR scans. For this deployment, we set up in a vineyard in Knights Valley located 5 $\mathrm{km}$ from the fire front allowing for close range observations of the smoke plume. The deployment site was located perpendicular to the estimated fire spread providing a safe location to scan from with a clear and safe exit strategy in case the fire moved into the valley. 
PPI scans at an elevation angle of $5.04^{\circ}$ were used to capture plume structures and evolution through the collection of radar reflectivity, velocity, and Doppler spectrum width (Fig. 5a-1). Vertical wind profiles taken with the Doppler lidar are shown in Figure 4. At the time of the PPI scans, surface wind speeds measured $15 \mathrm{~m} \mathrm{~s}^{-1}$ out of the northeast. Aloft, wind speeds increased to a maximum of $34 \mathrm{~m} \mathrm{~s}^{-1}$ and remained primarily out of the northeast. Similar to the first deployment, strong ambient wind conditions limited the vertical extent of the plume. Radar reflectivity values were of similar magnitude to that of the first deployment, with values ranging from -15 to $15 \mathrm{dBZ}$ (Figure 5a-d). Regions of maximum reflectivity returns were confined to the active fire front region and areas associated with isolated updraft cores. Along the edges of the smoke plume, much lower reflectivity values were observed as the debris and ash dispersed laterally. The reflectivity along the edges of the smoke plume increased in area with time. These returns are likely a result of increased debris and ash production from the intensification of the fire front. It is important to note that the feature of increased reflectivity to the north of the fire front is an artifact of the beam hitting a mountain ridge. This feature is only depicted in the last two scans (Fig. 5c, d), as the range of azimuth angles were increased to optimize observations. 


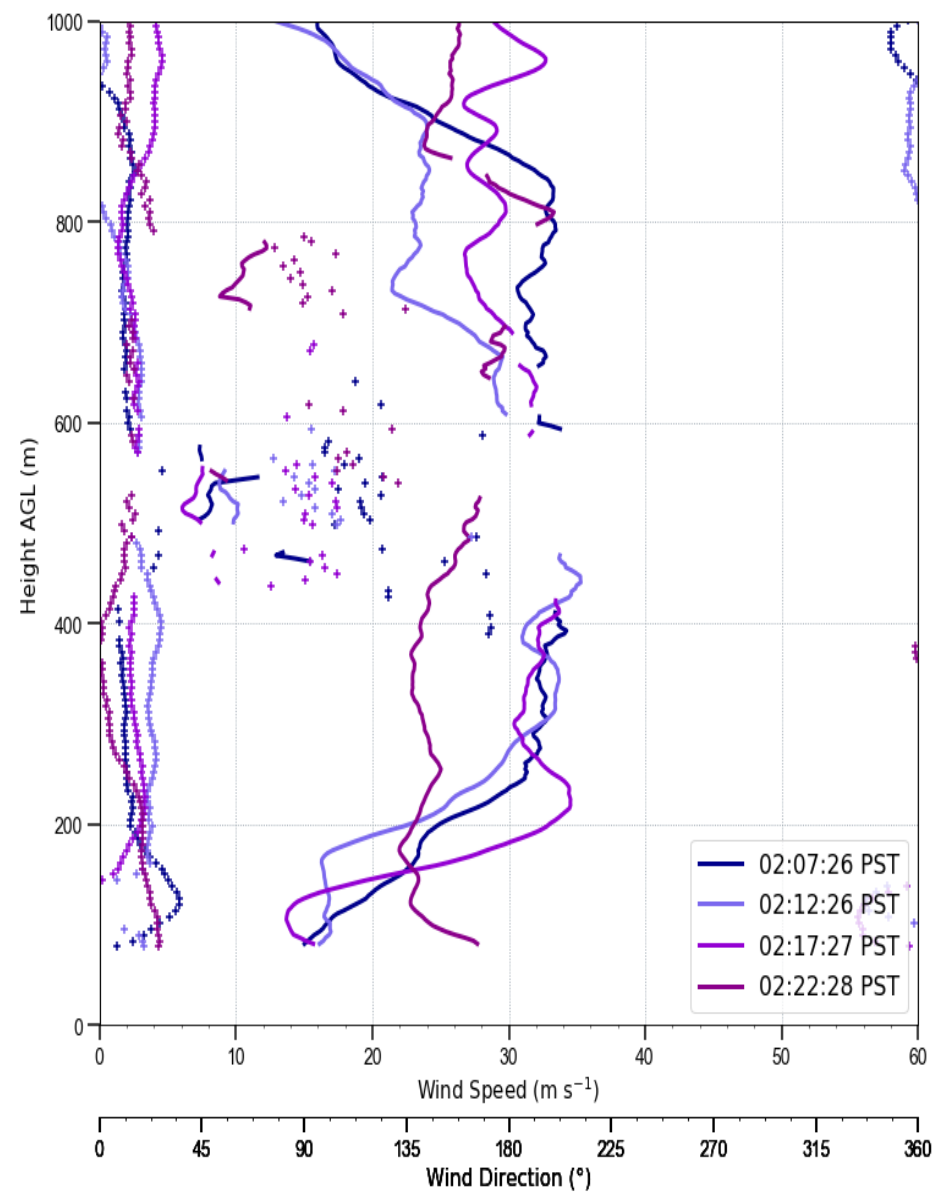

Figure 4. Doppler lidar vertical wind profiles measured during Kincade D2.

\section{e. D2 Doppler velocity analysis}

To analyze radial velocity from the radar, it is ideal for the along beam radial to be aligned with the mean ambient wind. As discussed above, the radar was positioned roughly $5 \mathrm{~km}$ to the east of the fire front (Fig. 1a) and almost perpendicular with the direction of 
the fire, therefore radial velocities are expected to be underestimated from these scans (Figure 5e-h).
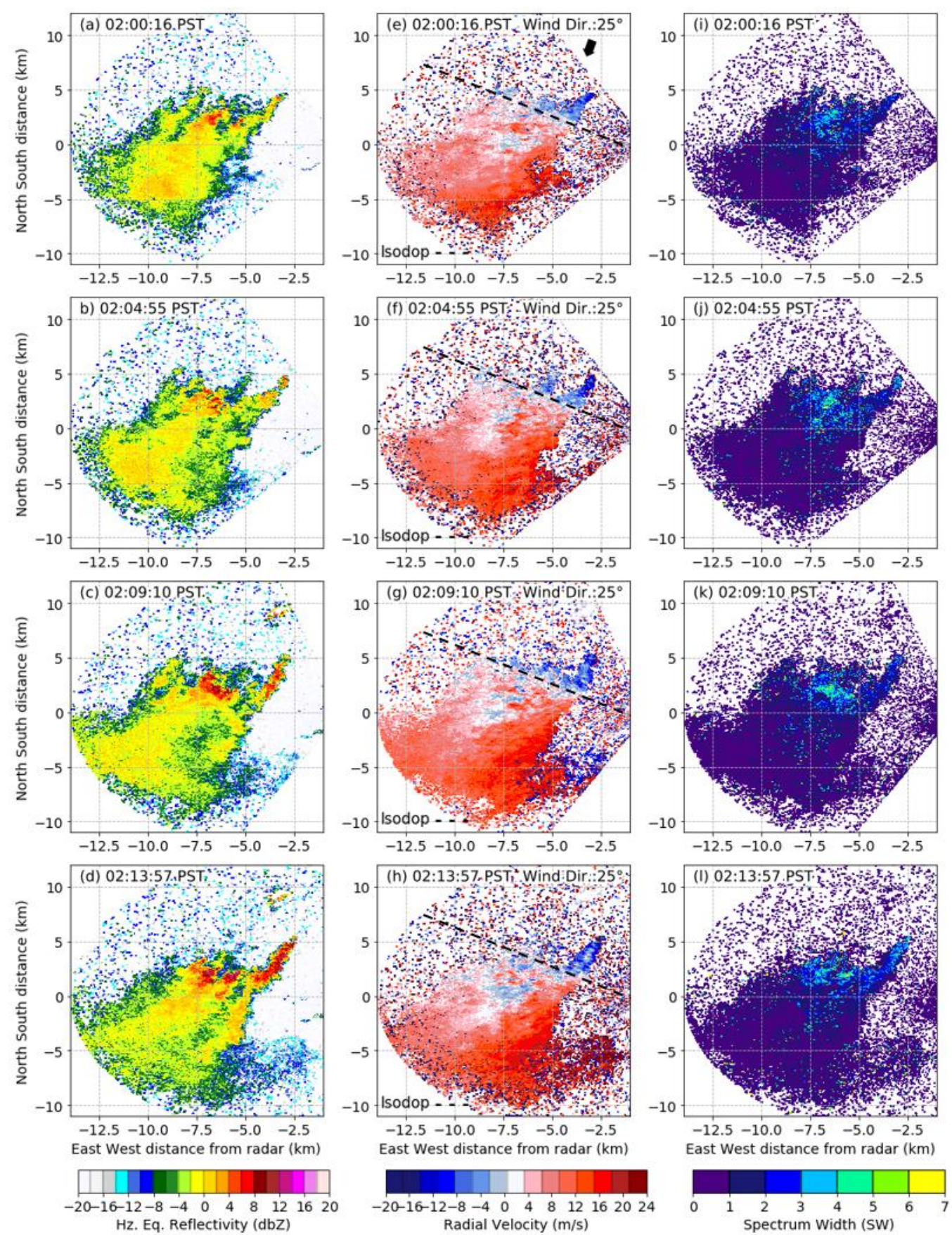

Figure 5. PPI scans at elevation angle 5.04 at 2:00 PST on 27 October 2019.

Signatures from D2 are of (a)-(e) horizontal equivalent reflectivity factor $\left(\mathrm{dBZ}_{\mathrm{H}}\right),(\mathrm{e})$ (h) radial velocity $\left(\mathrm{m} \mathrm{s}^{-1}\right)$, and (i)-(1) Doppler spectrum width (SW). 
Velocity returns indicated the plume was traveling west at $4-15 \mathrm{~m} \mathrm{~s}^{-1}$, however we know the plume was strongly influenced by the northeasterly winds present at this time. The strong winds acted to increase fire intensity and aided in carrying debris downwind, which is seen to extend over $6 \mathrm{~km}$ downwind from the fire front (areas of highest reflectivity). At the fire front, inbound velocities were measured to be approximately 8-12 $\mathrm{m} \mathrm{s}^{-1}$.

\section{f. D2 Spectrum width analysis}

The Doppler spectrum width indicates the highly turbulent regions within the smoke plume. Values were of similar magnitude as that of the first deployment, ranging from 0 to $7 \mathrm{~m} \mathrm{~s}^{-1}$. Maximum spectrum width values $\left(7 \mathrm{~m} \mathrm{~s}^{-1}\right)$ were confined to the areas where maximum reflectivities and radial velocities were also observed. On the downwind side of the plume where maximum reflectivity was near $0 \mathrm{dBZ}$, a sharp decrease in Doppler spectrum width was also observed. Along the plume edge where reflectivity and velocity returns were weak, localized maxima's $\left(\sim 5 \mathrm{~m} \mathrm{~s}^{-1}\right)$ in the spectrum width were observed (Fig. 5k, 1). These peaks are likely due to increased wind shear and debris transport on the downwind side of the plume and fire front.

\section{South Monroe Prescribed Burn Observations}

The Fire and Smoke Model Evaluation Experiment (FASMEE) is a collaborative field campaign that aims to identify how fuels, fire behavior, and meteorology interact in hopes to advance operational fire and smoke models (Prichard et al. 2019). To date, this experiment has consisted of two large, prescribed crown fires in Fishlake National Forest, Utah as a part of the Monroe Mountain Aspen Ecosystem Restoration Project. Prescribed 
fires are a form of land management in which a planned fire is intentionally set to vegetation. For this study, a prescribed crown fire was used to satisfy the research objectives of the FASMEE campaign and aid in aspen restoration. Radar observations were collected on a stand-replacement fire in mixed-conifer and aspen forest. Several research groups deployed other sensors such as fire behavior packages and fuel measurements to detail the characteristics of the prescribed crown fire.

The Monroe South prescribed fire was ignited in late morning of 7 November 2019 in Fishlake National Forest. Once completed, this prescribed fire burned a total of approximately 800 acres and produced a visible pyrocumulus that reached $\sim 8.7 \mathrm{~km}$ MSL. Our research team deployed to a location $3 \mathrm{~km}$ southeast of the burn unit (Fig. 1b). The CSU-MAPS Doppler lidar was used to obtain vertical wind profiles on the morning of ignition. Winds were northeasterly throughout the profile with speeds measuring $2-4 \mathrm{~m}$ $\mathrm{s}^{-1}$ near the surface and below $10 \mathrm{~m} \mathrm{~s}^{-1}$ aloft (Figure 6). Radar observations were collected from 1300 to 1600 MST or the time at which ignitions were conducted. Here we examine the smoke plume evolution of the South Monroe prescribed burn through radar analysis of reflectivity, velocity, and polarimetric parameters beginning at $1300 \mathrm{MST}$. 


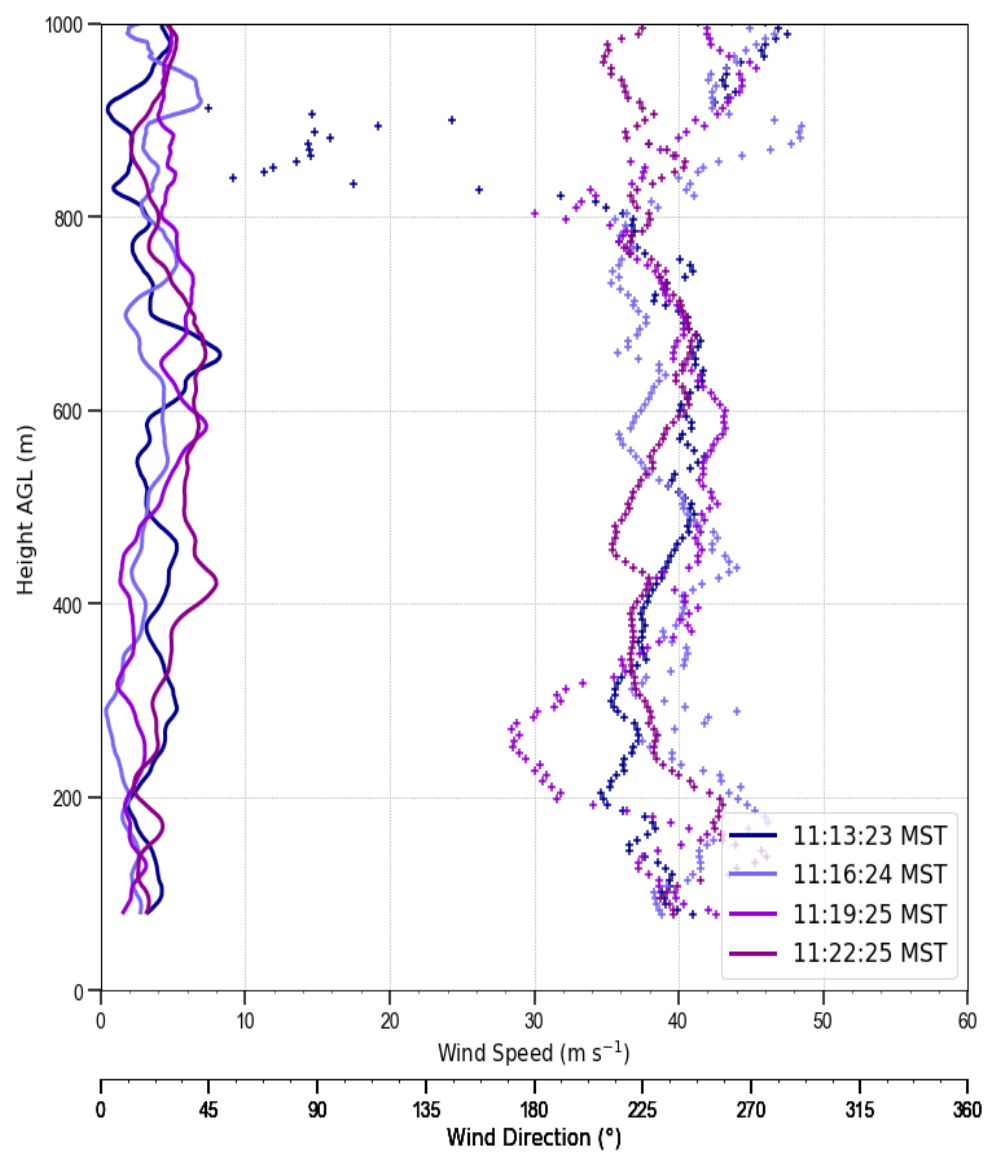

Figure 6. Doppler lidar vertical wind profiles measured during the South Monroe prescribed burn.

\section{a. Reflectivity observations from South Monroe burn}

Various scan procedures were used to detail the plume evolution throughout the day. The focus of this analysis examines a one-hour period of the smoke plume evolution using an RHI scan procedure (Fig. 7a-h). We had a target scan rate of $8^{\circ} \mathrm{s}^{-1}$ through elevation angles of $3^{\circ}$ to $80^{\circ}$ (Table 2). Several "puff' structures within the plume were visible after ignition; therefore scans were chosen to capture the rapid evolution of one of these primary 
features. Vertical slices through the plume illustrate the distribution and magnitude of reflectivity along the radar beam. Light winds provided a favorable atmosphere for the plume to rise vertically to $6 \mathrm{~km}$ AGL during this one-hour period. In addition, a stable layer is observed in the reflectivity data at approximately $2 \mathrm{~km}$ AGL and persisted throughout the day. Observed values of reflectivity were between -12 and $20 \mathrm{dBZ}$ within the plume (Figure 7a-d). In the first scan (Fig. 7a; 1300 MST), maximum reflectivities were confined to the base of the plume where larger, heavier debris was likely located. As the convection column intensified, larger debris can be seen to propagate vertically throughout the column (Fig. 7b, c). Low reflectivity values along the stable layer and edges of the smoke plume persists for all scans. In areas where reflectivity decreases in magnitude between scans (Fig. 7d), particle fallout is likely occurring as ash and debris disperse aloft.

\section{b. Velocity observations from South Monroe burn}

Vertical slices through the smoke plume allowed for observations of the kinematic structures of the smoke plume and surrounding areas to be made. In the early phase of the plume rise (Fig. 7e), velocity returns were weak within the plume and values were $\pm 6 \mathrm{~m}$ $\mathrm{s}^{-1}$ to and from the radar. As the fire intensified and the plume extended vertically, greater velocities $\left(\sim 25 \mathrm{~m} \mathrm{~s}^{-1}\right)$ were measured $2-4 \mathrm{~km}$ above the plume base (Fig. $\left.7 \mathrm{~g}\right)$.

Velocity maxima were measured along the center axis of the plume core and likely indicate the location of the updraft core. The edges of the plume are illustrated by much lower measured velocities and weaker returns. Near the base of the plume (Fig. 7e, f), contrasting inbound and outbound velocities indicate a zone of localized convergence. In 
contrast, the top of the plume is depicted by diverging velocities or divergence aloft for all scans. Above the stable layer on the downwind side of the plume, an area of inbound velocities can be seen at $3 \mathrm{~km}$ AGL (Fig. 7g, h). This region of inbound velocities proceeds areas of low reflectivity, likely indicating the plume is entraining clean air. In the last scan (Fig. 7h; 1348 MST), inbound velocities decreased and were associated with reflectivity decreases of $\sim 8 \mathrm{dBZ}$. This feature is indicative of clean air entrainment and ash particle fallout.

\section{c. Polarimetric Observations from South Monroe burn}

Differential reflectivity, correlation coefficient, and Doppler spectrum width signatures of the South Monroe plume are shown in Fig. 8a-1. Differential reflectivities were positive within the smoke plume, although the distribution was highly variable. Similar to the observations of the Kincade wildfire, updraft locations and regions where reflectivity values are positive are characterized by ZDR values of $0-3 \mathrm{~dB}$. Outside of

these locations, differential reflectivity values are higher (> $3 \mathrm{~dB})$ indicating horizontally oriented targets. 

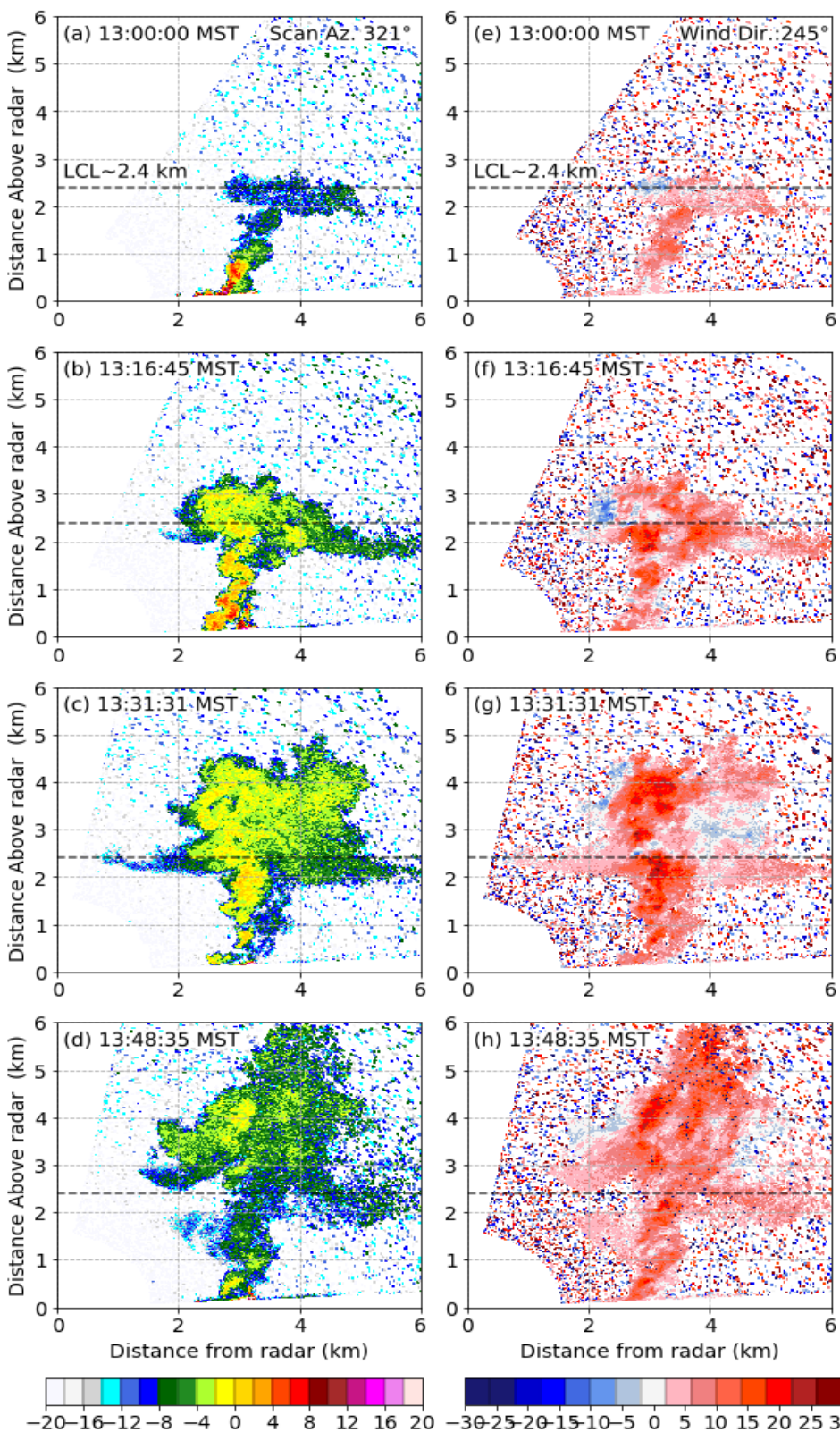

Hz. Eq. Reflectivity (dbZ)

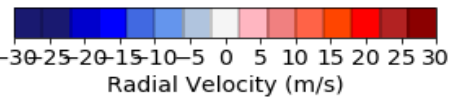

Figure 7. KASPR radar signatures from the South Monroe prescribed burn of (a)-(d) horizontal equivalent reflectivity factor $\left(\mathrm{dBZ}_{\mathrm{H}}\right)$ and $(\mathrm{e})-(\mathrm{h})$ radial velocity $\left(\mathrm{m} \mathrm{s}^{-1}\right)$ beginning at 13:00 MST on 7 November 2019.

Copolar correlation is highly variable in the plume and no distinct patterns are evident. The magnitude of correlation coefficient values within the plume remained 
above 0.3 and below 0.8 . On the downwind edges of the plume, increased correlation coefficient values are observed. When compared against the correlation coefficient returns from the Kincade deployments, values are a magnitude higher for the South Monroe burn. While this fire did produce a visible pyrocumulus, no signature in the correlation coefficient indicate this process. A shift to larger correlation coefficients is expected if liquid water was present, yet values remained below 0.8 for all scans. It is likely that the cloud droplets were likely too small to be measured by the radar. Slightly higher values can be seen in the last scan (Fig. 8h) above $3 \mathrm{~km}$, however returns are highly variable and do not reveal a strong signature of liquid presence. One possible explanation for similar $\rho h v$ values observed through the depth of the plume is that the plume is likely populated with pyrometeors through its entire depth and while the radar does not determine the cloud base as observed visually, the continuous $\rho h v$ indicates that the pyrometeors extend all the way to the top of the plume and within the observed pyrocumulus. 

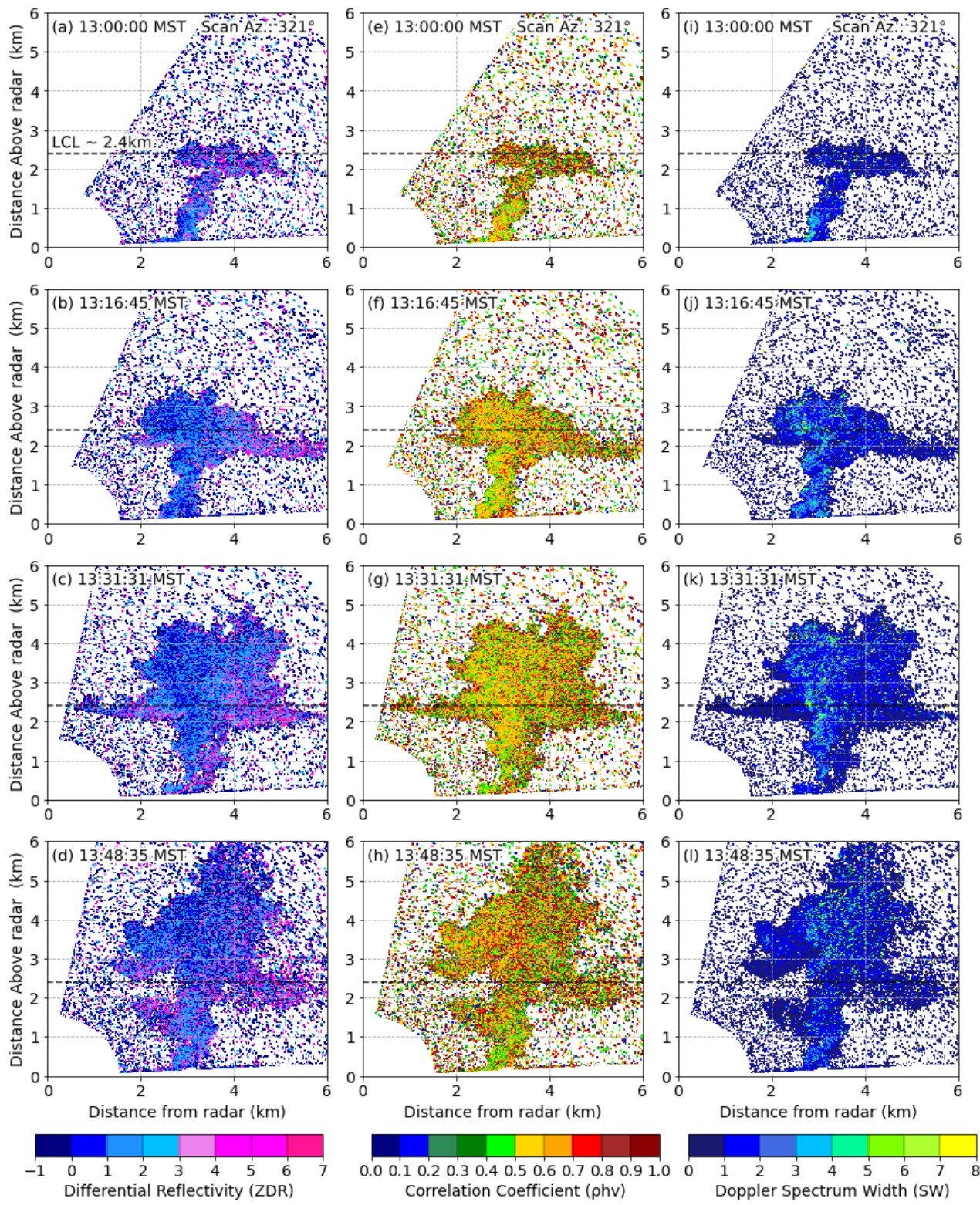

Figure 8. Same RHI scan as Fig. 4 beginning at 13:00 MST on 7 November 2019. The following fields are (a)-(d) differential reflectivity $\left(\mathrm{Z}_{\mathrm{DR}}\right)$, (e)-(h) copolar correlation coefficient ( $\rho$ hv), and (i)-(l) Doppler spectrum width.

The Doppler spectrum width returns revealed that the most turbulent and highly

variable areas within the smoke plume are located in the central updraft core (Fig. 8i-1).

Spectrum width values were of similar magnitude to that of the Kincade wildfire, with 
values ranging from 0 to $6 \mathrm{~m} \mathrm{~s}^{-1}$. Spectrum width values were the lowest during the first scan, with the maximum value being $5 \mathrm{~m} \mathrm{~s}^{-1}$ in the updraft core zone (Fig. 6, 3km). As the fire intensified and the plume increased in size, Doppler spectrum width increased with each subsequent scan likely caused by increased updraft velocities associated with the updraft core. Spectrum width maxima remained confined to the updraft core located within the central part of the plume while the minimum values persisted along the edges of the plume. In the last scan (Fig. 81), increased values can be seen to be exist aloft, at approximately $5 \mathrm{~km}$ AGL. The increase in spectrum width at this level is likely a result of increased overturning of the plume and could be caused by wind shear aloft.

\section{d. Mean variables from South Monroe fire}

Figure 9 shows the mean value of each variable along three different elevation angles for the one-hour period. Averaging each of the variables along the elevation beam provided a way to assess what the plume was doing at various heights above the fire. Specifically, we examined elevation angles $3^{\circ}, 30^{\circ}$, and $60^{\circ}$. For all variables, the lowest elevation angle depicts the greatest returns within the plume. Reflectivity, correlation coefficient, and spectrum width increased along the beam while in the plume. In contrast, average velocity and differential reflectivity decreased. These data indicate the most turbulent area of the plume is collocated with the regions of maximum reflectivity and correlation coefficient. Mean values along this elevation reveal reflectivity were between 
-2 and $20 \mathrm{dBZ}$ and radial velocities were $0-7 \mathrm{~m} \mathrm{~s}^{-1}$. ZDR, $\rho$ hv, and $\mathrm{SW}$ had mean values of $1 \mathrm{~dB}, 0.6$, and $2.5 \mathrm{~m} \mathrm{~s}^{-1}$, respectively.
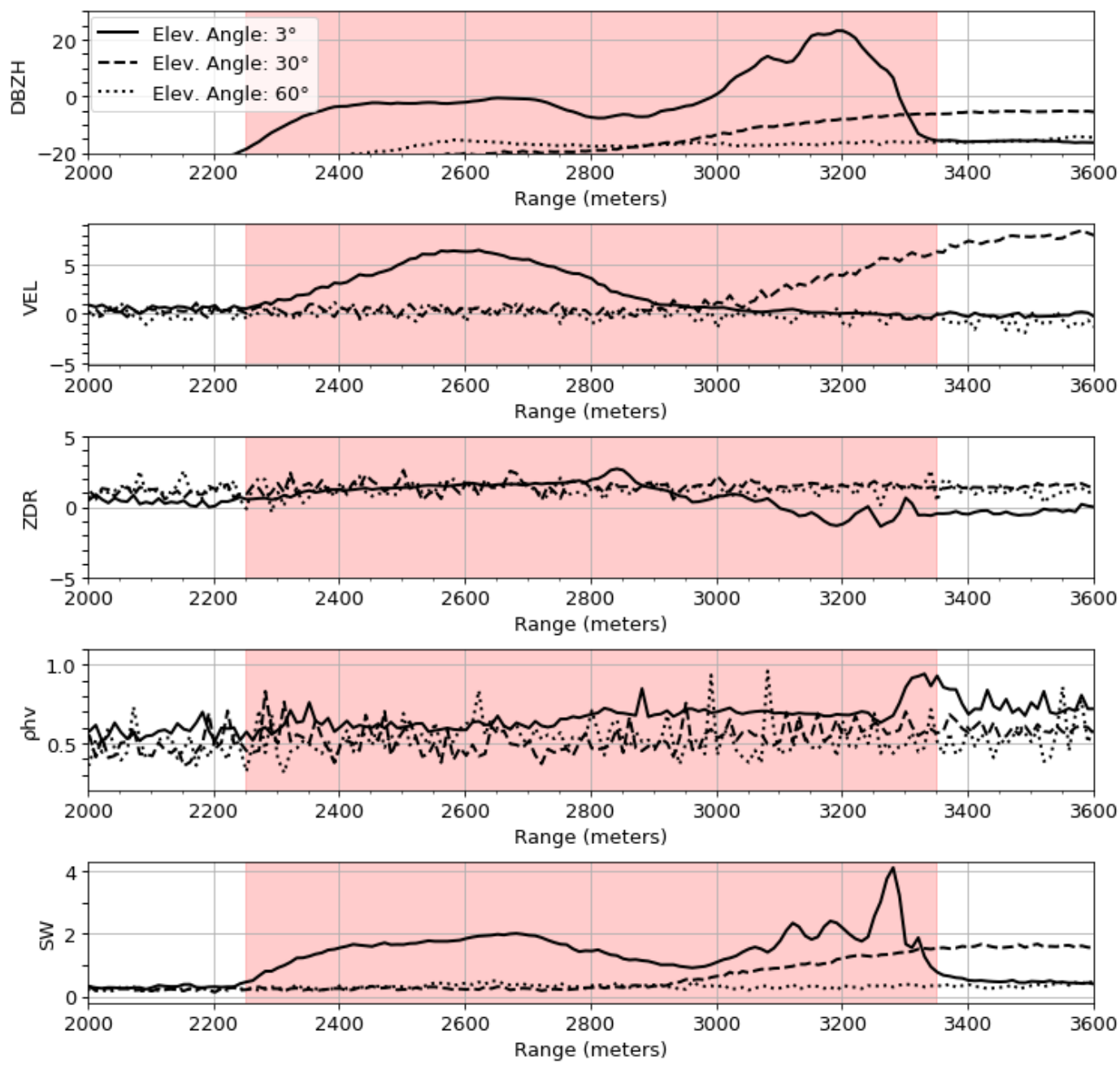

Figure 9. Mean radar variables along the $3^{\circ}, 30^{\circ}$, and $60^{\circ}$ elevation beam. Variables top to bottom are as following: horizontal radar reflectivity, radial velocity, differential reflectivity, copolar correlation coefficient, and Doppler spectrum width. The red shading indicates the location where the beam was within the smoke plume.

Elevation angles $30^{\circ}$ and $60^{\circ}$ illustrated different patterns than the lowest beam amongst variables. Reflectivity along these elevation angles were weak and values remained below $0 \mathrm{dBZ}$ within the smoke plume. The average velocities along these 
beams have a mean of $0 \mathrm{~m} \mathrm{~s}^{-1}$. Along the $30^{\circ}$ beam, average velocities increased with distance along the radial beam $(\sim 3 \mathrm{~km})$. The average differential reflectivity returns are of similar magnitude for all elevation angles; however, the higher elevation angles indicate a more strongly polarized signal with a mean value of $2 \mathrm{~dB}$. In contrast, the average correlation coefficients were lower at higher elevation angles, with an average value closer to 0.5. Mean Doppler spectrum width was less than $1 \mathrm{~m} \mathrm{~s}^{-1}$ and decreased with height. With the exception of the $30^{\circ}$ beam, Doppler spectrum width decreased downwind of the plume.

Studies documenting mean polarimetric variables of wildfire smoke plumes have found similar values to that of the South Monroe prescribed burn. Melnikov et al. (2008) detailed mean ZDR and $\rho h v$ to be $1.4 \mathrm{~dB}$ and 0.33 in a vertical cross section of a fire plume. Similarly, Jones and Christopher (2009) observed a mean ZDR of $1.7 \mathrm{~dB}$ and $\rho h v$ of 0.49 in a low-elevation PPI scan. This study also recorded mean reflectivity values between -3 and $18 \mathrm{dBZ}$ in the smoke plume, with few returns exceeding $20 \mathrm{dBZ}$. The most recent study that documented mean polarimetric variables of smoke plumes was that by Zrnic et al. (2020) in which a $10 \mathrm{~cm}$ and $5 \mathrm{~cm}$ radar were used to observe three wildfires. Mean radar reflectivity values were of similar values to the ones in this study, however mean ZDR values were greater than $2 \mathrm{~dB}$ and mean $\rho h v$ were less than 0.5 . Values from our study and those previously conducted are all of similar magnitude with the exception of correlation coefficient. Observations of correlation coefficients with KASPR were slightly higher than those documented in other studies, which is likely a result of the difference in wavelengths and beamwidths amongst radars. Additionally, in our observations several variables are 
shown to decrease on the leeward side of the plume. McCarthy et al. (2018) observed a decrease in Doppler spectrum width in the leeward zone of a smoke plume, which is also evident in our observations.

\section{Briceburg Wildfire Observations}

The Briceburg wildfire ignited on the afternoon of 6 October 2019 in Mariposa County, California at approximately $37.605^{\circ} \mathrm{N}, 119.966^{\circ} \mathrm{W}$ (CalFire, a). KASPR was deployed on 9 October to observe and collect data on the Briceburg smoke plume. Dry and windy conditions were forecasted to persist throughout the day, providing favorable fire weather conditions for rapid fire growth. On this day, the fire burned over 1,000 acres and produced a visible pyrocumulus from satellite imagery. Complex terrain and major road closings in the area made it difficult to obtain a radar site close to the fire. The chosen site was located on a ridge approximately $13 \mathrm{~km}$ southwest of the fire at $37.535^{\circ} \mathrm{N}, 120.030^{\circ} \mathrm{W}$. KASPR operated RHI scanning procedures at a targeted scan rate of $1^{\circ} \mathrm{s}^{-1}$ through elevation angles $0.05^{\circ}$ to $11.65^{\circ}$ (Table 2). This analysis focuses on a period where the plume grew vertically and reached a height of $3 \mathrm{~km}$ AGL.

\section{a. Radar Observations from Briceburg Wildfire}

Figure 10 a-h illustrates radar reflectivity and velocity observations of the Briceburg wildfire beginning at 13:25 PST. Radar reflectivity measured -14 to $6 \mathrm{dBZ}$ within the plume, with the highest values located near the plume base. Cores of reflectivity $>-4 \mathrm{dBZ}$ propagated vertically through the entire depth of the plume (Fig. 10a) and advected downwind with the ambient flow (Fig. 10b). At 13:40:26 PST (Fig. 10c), a coherent reflectivity core was observed to extend from the surface to a height of $\sim 1.2 \mathrm{~km}$ AGL. This 
plume core was $\sim 250-500 \mathrm{~m}$ in width and indicates a region where a coherent and continuous high-reflectivity core representing pyrometeors extended through the height of the plume. This observed structure suggests that pyrometeors and debris are advected vertically through the plume and ejected out the top and downwind of the plume updraft core. Outside of the plume updraft reflectivity cores, the plume is characterized by weak returns, which is likely a result of either the scanning range or more dispersed pyrometeors. Radial velocity returns indicated the plume particles were traveling away from the radar at 3 to $12 \mathrm{~m} \mathrm{~s}^{-1}$. The first scan (Fig. 10e) depicts contrasting inbound and outbound velocities below $0.5 \mathrm{~km}$ AGL, indicating converging flow at the plume base. An area of weak inbound 
velocities $\left(\sim 3 \mathrm{~m} \mathrm{~s}^{-1}\right)$ can be seen in all scans from 0.5 to $1.5 \mathrm{~km}$ AGL illustrating plume overturning and entrainment on the upwind and downwind edges of the plume.
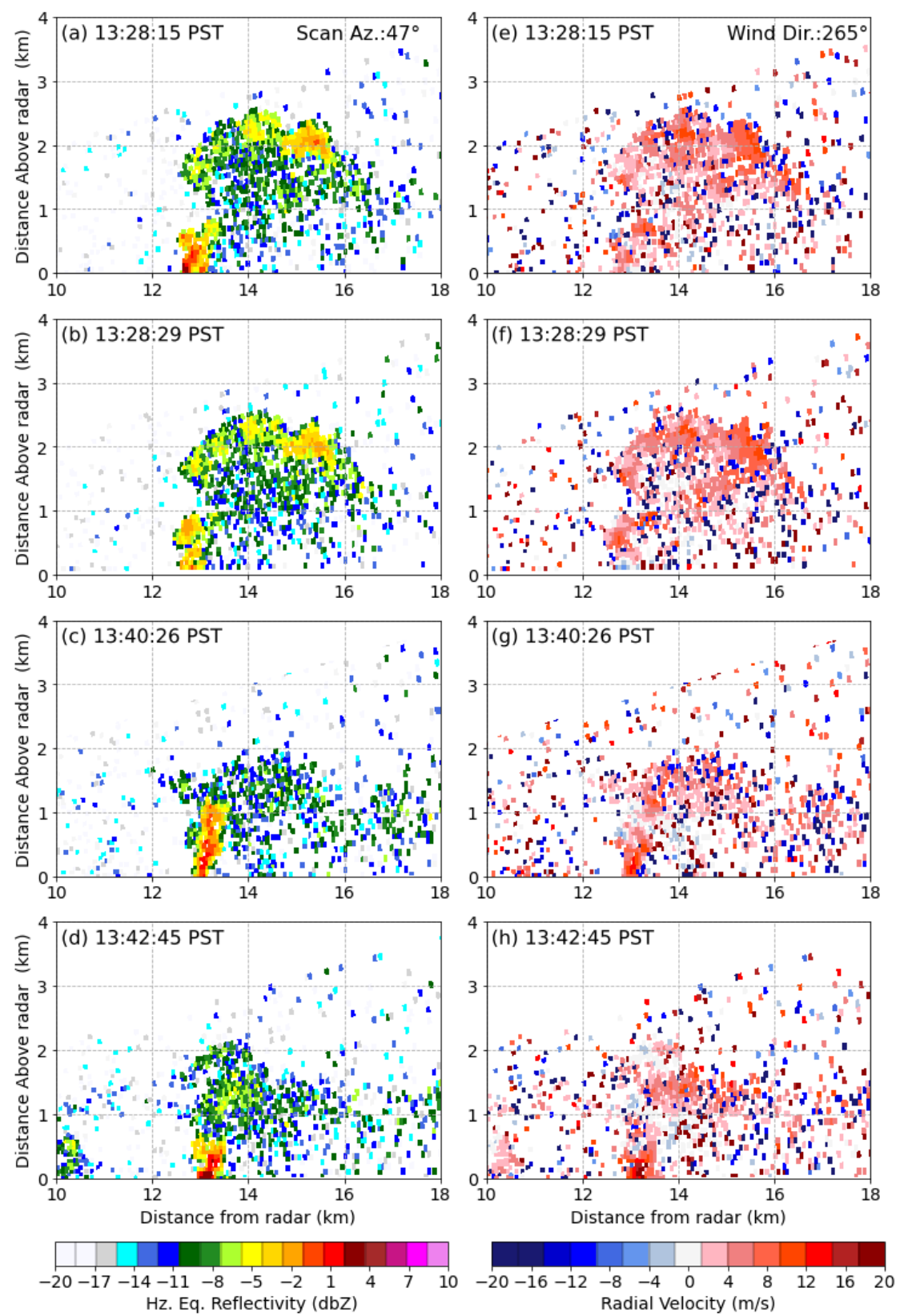

Figure 10. KASPR radar signatures from the Briceburg wildfire beginning at 13:28 PST on 9 October 2019. The fields depicted are (a)(d) horizontal reflectivity $\left(\mathrm{dBZ}_{\mathrm{H}}\right)$ and $(\mathrm{e})$-(h) radial velocity $\left(\mathrm{m} \mathrm{s}^{-1}\right)$. 
Observations of the Briceburg wildfire illustrate coarser range resolution measurements of reflectivity and radial velocity. Operating in mode polarimetric pulse pair examines the polarimetric parameters at the lowest sensitivity amongst the settings, which further lowered the resolution of our scans. Due to these limiting factors, observations were not as detailed as the others shown in this study. However, these data indicate that even at long-range, KASPR observations of wildfire smoke plumes can provide information on plume dynamics and evolution. This case study highlights how narrow reflectivity cores propagate through the entire depth to the plume and eject smoke and pyrometeors out the top and downwind.

\section{Precipitation Observations}

On 18 September 2019, KASPR captured the passing of a precipitating stratiform cloud deck near San José State University. Fig. 11a-d illustrates an RHI scan that details radar reflectivity, correlation coefficient, differential reflectivity, and Doppler spectrum width of the precipitating cloud deck at 10:50 PST. While radar signatures of precipitation are well documented in literature, this dataset allows for the comparison of Ka-band precipitation and wildfire smoke plume signatures to be made. 

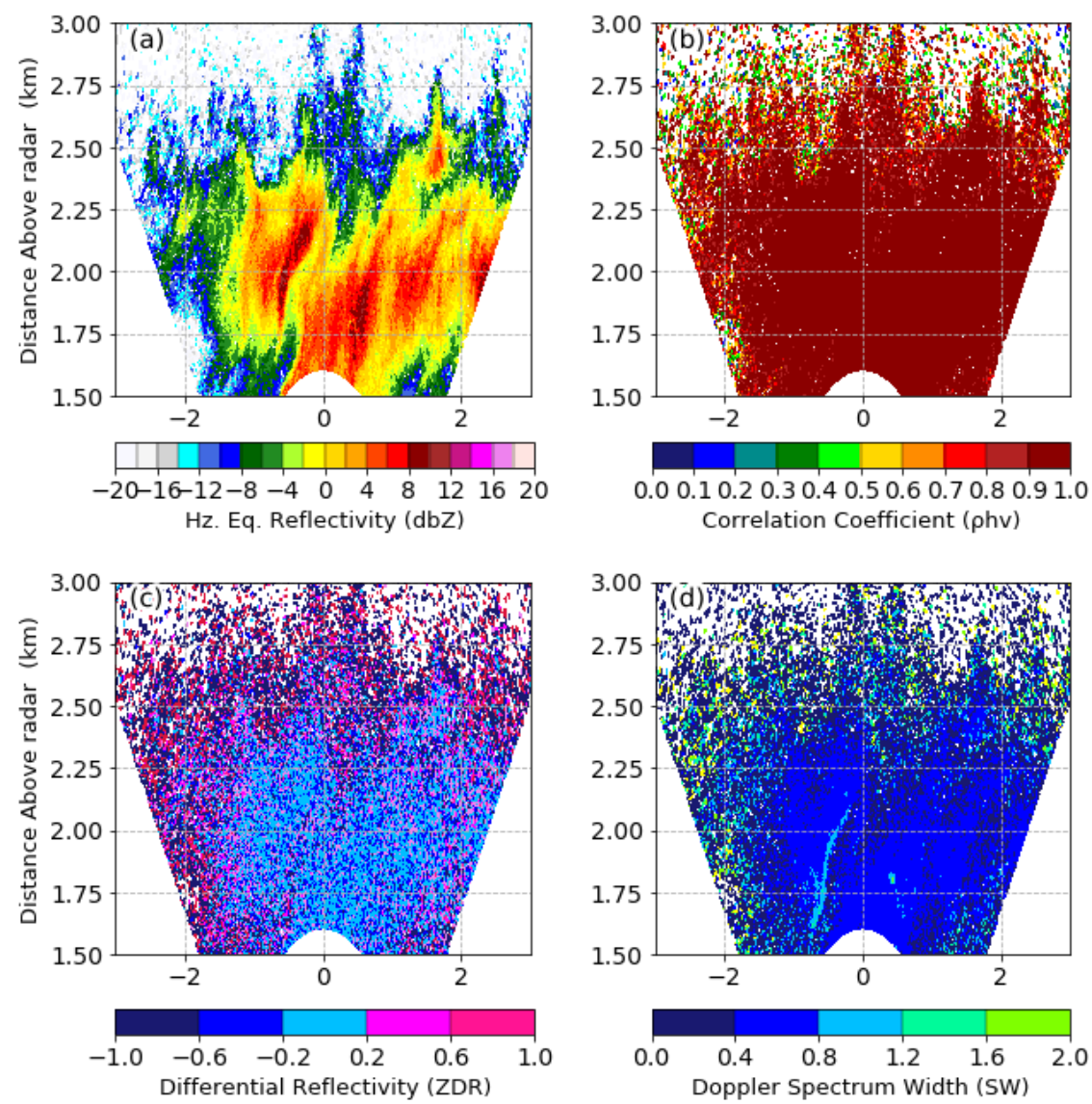

Figure 11. KASPR radar signatures of a precipitating cloud deck beginning at 10:50 PST on 18 September 2019. The fields depicted are (a) horizontal reflectivity $\left(\mathrm{dBZ}_{\mathrm{H}}\right)$, (b) copolar correlation coefficient $(\rho h v)$, (c) differential reflectivity $\left(\mathrm{Z}_{\mathrm{DR}}\right)$, and (d) Doppler spectrum width.

Radar reflectivity had a maximum value of $12 \mathrm{dBZ}$ in cloud, with values below zero along the edges of the cloud deck (Fig. 11a). In contrast to the observed $\rho h v$ from the wildfire deployments, $\rho h v$ values for this case were near 1 and indicated near-spherical droplets were present in each sample volume (Fig. 11b). These data are consistent with that of previous observations of rain using radar. Differential reflectivity values indicated that the targets observed did not favor one polarization over the other and revealed a near spherical shape (Fig. 11c). Lastly, we obtained Doppler spectrum width observations to 
detail the turbulent structure of the stratiform cloud deck (Fig. 11d). Values in cloud ranged from 0 to $1.2 \mathrm{~m} \mathrm{~s}^{-1}$, with maximum values associated with reflectivity maxima. As expected, Doppler spectrum width values from this case were much lower than the produced values from the wildfire observations (Figs. 3i-1, 5i-1, 8i-1). Due to the nonconvective nature of stratiform precipitation, radar reflectivity and doppler spectrum width measurements were below the values observed from the wildfire deployments.

A second dataset of precipitation was obtained on 06 April 2020 in San José, CA. Figures 12 a-i illustrates radar reflectivity, radial velocity, and Doppler spectrum width of the precipitating system beginning at 12:50:20 PST. Similar to the previous dataset of precipitation, radar reflectivity revealed a maximum value of $12 \mathrm{dBZ}$ in cloud (Figs. 12ac). Radar reflectivity also revealed the locations where larger water droplets are present, indicated by areas of increased radar reflectivity. Radial velocity structures indicate negative vertical velocity or sinking motions above the radar (Figs. 12 d-f). Radial velocity also revealed positive velocities along the radial beam, indicating the system was moving away from the radar at 5-10 $\mathrm{m} \mathrm{s}^{-1}$. Lastly, Doppler spectrum width measurements revealed the turbulent locations within the precipitating system (Fig. 12g-i). Doppler spectrum width ranged from $0-4 \mathrm{~m} \mathrm{~s}^{-1}$ in cloud, with increased values confined to the 
location just above the radar. As with the previous studies, Doppler spectrum width were associated with areas of increased radar reflectivity.
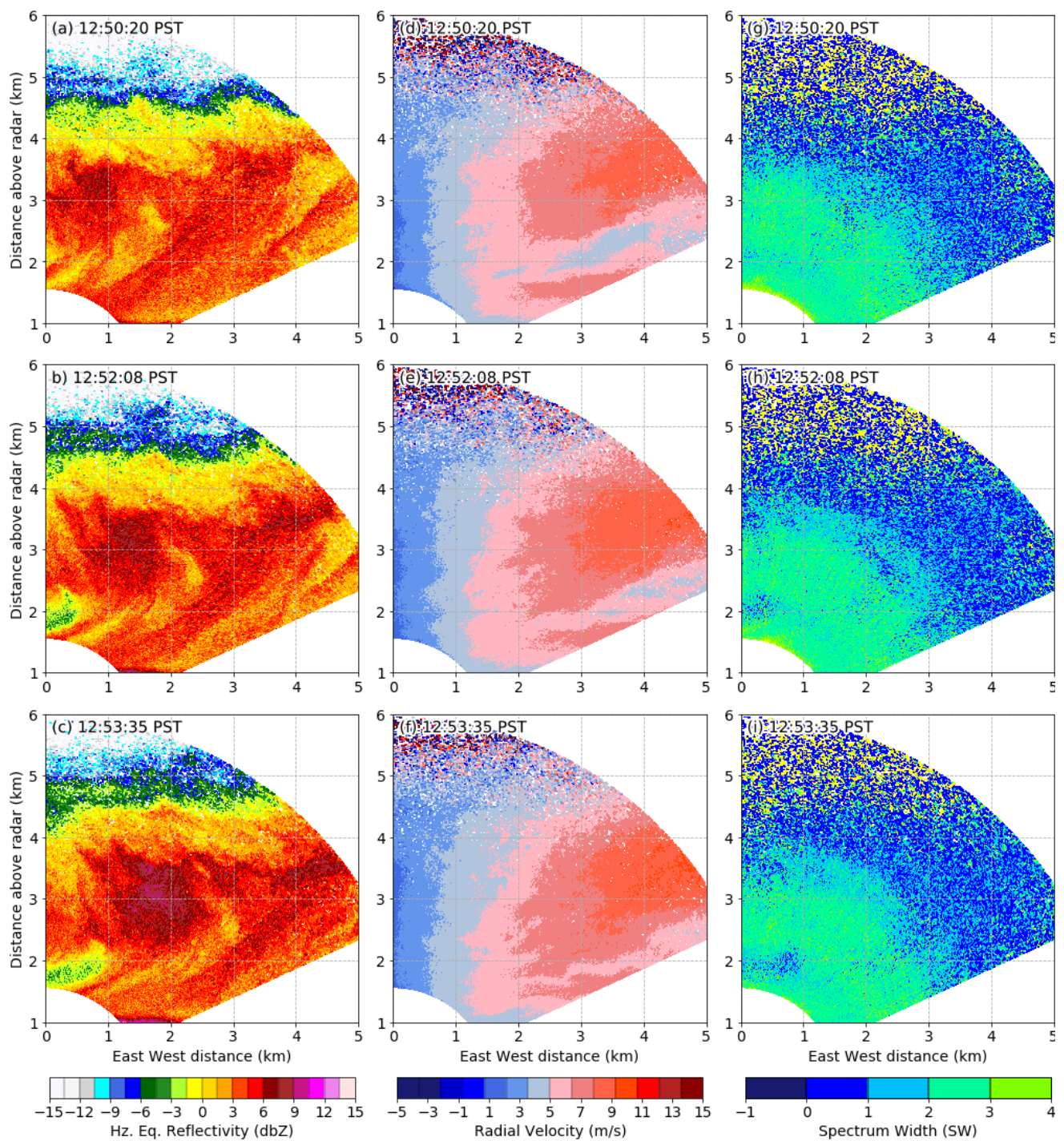

Figure 12. KASPR radar signatures of a precipitating cloud deck beginning at 12:50:20 PST on 06 April 2020. The fields depicted are (a-c) horizontal reflectivity $\left(\mathrm{dBZ}_{\mathrm{H}}\right),(\mathrm{d}-\mathrm{f})$ radial velocity, and $(\mathrm{g}-\mathrm{i})$ Doppler spectrum width. 
Comparing Ka-band specific signatures of wildfires and precipitation permits the interpretation of various radar targets. While Ka-band signatures of precipitation have been well documented in previous literature, no study has aimed to compare the signatures to that of wildfire smoke plumes. Ash and debris produced by wildfires are highly irregular scattering materials that exhibit very different polarimetric characteristics than that of hydrometeor targets, enabling the distinction between. For example, $Z D R$ values associated with wildfire smoke plumes are nonspherical in nature and favor one polarization over the other. $Z D R$ measurements taken of wildfire smoke plumes exhibited positive values, indicating that ash and debris lofted from wildfires primarily lie in the horizontal plane. Correlation coefficients associated with wildfire ash and debris are low $(<0.8)$, indicating that a large variety of particle shapes and sizes are observed in each sample volume (Figs. 3e-h, 8e-h), whereas hydrometeor targets have $\rho h v$ values near 1 (Fig. 11b). Non-polarimetric parameters, such as reflectivity and radial velocity, revealed similar values for the wildfire and precipitation observations. Doppler spectrum width observations of wildfire smoke plumes revealed the highly turbulent nature of wildfires. Spectrum width values ranged from 2-7 $\mathrm{m} \mathrm{s}^{-1}$ across all wildfire deployments, whereas spectrum width values obtained from the precipitation cases did not exceed $4 \mathrm{~m} \mathrm{~s}^{-1}$.

\section{Discussion}

Through the analysis of radar reflectivity, radial velocity, and polarimetric properties, insight into Ka-band radar specific signatures of smoke plumes are shown. A conceptual diagram was created to show an overview of the findings from this study highlighting the dual-polarization observations of wildfire smoke plumes (Figure 13). Specifically, this 
diagram details the areas of turbulent motions, the various shapes of targets within the plume, and the overall transport of pyrometeors found in our observations. Within this study, distributions of radar reflectivity were similar across all deployments, revealing values between -15 and $20 \mathrm{dBZ}$ within the plume and some reflectivity cores exceeding this upper limit. Areas of maxima reflectivity were associated with maxima in radial velocity and Doppler spectrum width and were located near the base of the plume and updraft core zone for all plumes sampled. Radial velocity structures revealed converging flow into the base of the plume and diverging flow aloft. Clean air entrainment was also observed in the radial velocity signatures from the Kincade D1 and D2 and South Monroe deployments.

The observed polarimetric parameters were similar to those of previous studies using radar to investigate polarimetric properties of wildfire plumes (Melnikov et al. 2008; Jones and Christopher 2009; McCarthy et al. 2018; Zrnic et al. 2020). Positive values of $Z D R$ paired with low $\rho h v$ indicate wildfire targets are of various shapes and sizes in each sample volume. Positive $Z D R$ values were associated with low reflectivity values and remained outside of the primary updraft location, with maximum values near $6 \mathrm{~dB}$. Positive ZDR values indicate the needle-like appearance of ash and smoke that has been concluded from previous studies (Melnikov et al. 2008; Jones and Christopher 2009). Relatively low ZDR values inside the primary updraft location were likely a result of turbulent motions and shear. Correlation coefficient values remained below 0.8 for in plume observations, with the lowest values $(\sim 0.3)$ located near plume base revealing a wide array of particle shapes and motions were present. Furthermore, KDP values were 
calculated for the South Monroe plume only (not shown) and indicated that KDP was small, $\left(<1.0\right.$ deg. $\left.\mathrm{km}^{-1}\right)$ throughout the plume.

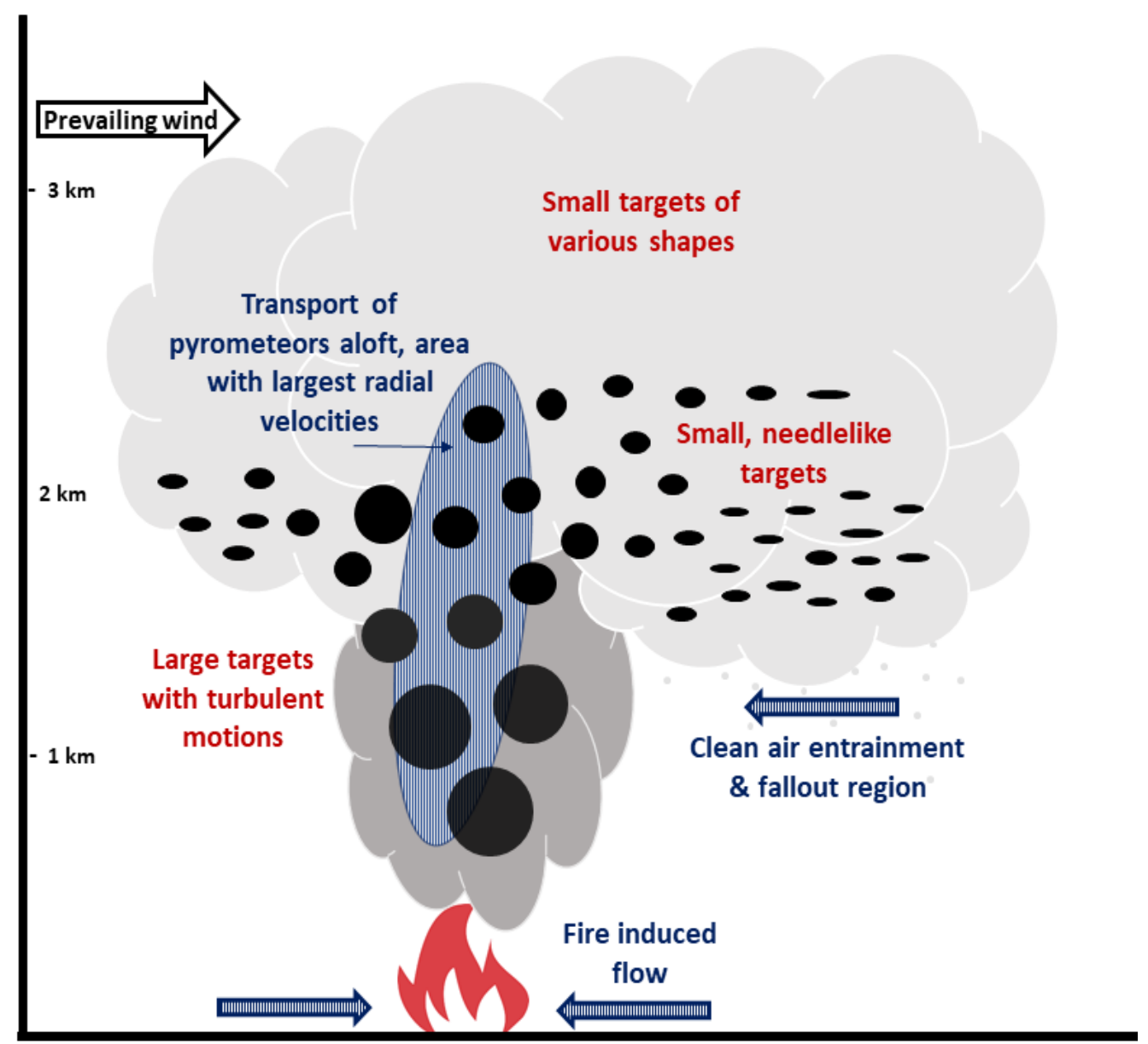

Figure 13. Conceptual diagram detailing the observed dual-polarimetric and kinematic structures.

Dual polarimetric observations of precipitation allowed for the comparison of wildfire and precipitation Ka-band specific signatures. Radar reflectivity were of similar values for both the wildfires and precipitation observations, with values above $0 \mathrm{dBZ}$ for in plume and in cloud scans. Correlation coefficient values from the precipitation 
observations were near 1, indicating near-spherical droplets were measured. In contrast to the $Z D R$ observations of wildfire smoke plumes, hydrometeor targets do not favor one polarization over another and had values near $0 \mathrm{~dB}$. Lastly, when comparing Doppler spectrum width, the wildfire observations revealed more turbulent structures than that of the precipitation.

\section{Conclusions}

Dual polarimetric Ka-band radar measurements of two wildfires and one prescribed crown fire were used to observe the fine-scale kinematics and dual polarimetric properties of smoke plumes. This study highlights the advantages of utilizing a portable, millimeter wavelength radar for monitoring and investigating wildfire plume dynamics and microphysics. The results from this study highlight the high temporal and spatial resolution observations of wildfire smoke plumes obtained from millimeter wavelength radars. Utilizing compact and mobile radars allows for continuous, close-range and highly resolved observations of wildfire smoke plumes that the operational NEXRAD WSR-88D network cannot always provide. In addition, millimeter wavelength radars are more ideally suited for studying small pyrometeors lofted from wildfires than the operational $10 \mathrm{~cm}$ weather radars. Further investigation into the fine-scale kinematics and microphysical properties of wildfire smoke plumes will aid in the development and validation of better predictive tools for wildfire behavior by incorporating these types of observations into next-generation spotting and transport models. 


\section{References}

Adams, R. J., W. F. Perger, W. I. Rose, A. Kostinski, 1996: Measurements of the complex dielectric constant of volcanic ash from 4 to $9 \mathrm{GHz}$. J. Geophys. Res., 124, 266-286, https://doi.org/10.1029/2018JD029285.

Banta, R. M., L. D. Olivier, E. T. Holloway, R. A. Kropfli, B. W. Bartram, R. E. Cupp, and M. J. Post, 1992: Smoke-column observations from two forest fires using Doppler lidar and Doppler radar. J. Appl. Meteor., 31, 1328-1349.

Baum, T. C., L. Thompson, and K. Ghorbani, 2015: The nature of fire ash particles: Microwave material properties, dynamic behavior, and temperature correlation. IEEE J. Sel. Top. Appl. Earth Obs. Remote Sens., 8, 480-492, https://doi.org/10.1109/JSTARS.2014.2386394.

Bluestein, H. B., 1999: A History of Severe-Storm-Intercept Field Programs. Wea. Forecasting, 14, 558-577, https://doi.org/10.1175/15200434(1999)014<0558:AHOSSI>2.0.CO;2.

Bryan, S., A. Clarke, L. Vanderkluysen, C. Groppi, S. Paine, D. W. Bliss, 2017: Measuring Water Vapor and Ash in Volcanic Eruptions with a Millimeter-Wave Radar/Imager. IEEE Transactions on Geoscience and Remote Sensing, 55, 3177 3185, https://doi.org/10.1109/TGRS.2017.2663381. 
Cal Fire, a. Incidents-Briceburg Fire. Accessed 20 March 2019, https://fire.ca.gov/incidents/2019/10/6/briceburg-fire/.

Cal Fire, b. Incidents-Kincade Fire. Accessed 23 March 2019, https://www.fire.ca.gov/incidents/2019/10/23/kincade-fire/.

Cal Fire, c. Incidents-Camp Fire. Accessed 1 September 20, https://www.fire.ca.gov/incidents/2018/11/8/camp-fire/.

Charland, A. M., and C. B. Clements, 2013: Kinematic structure of a wildland fire plume observed by Doppler lidar. J. Geophys. Res. Atmos., 118, 3200-3212, https://doi.org/10.1002/jgrd.50308.

Clements, C. B., 2010: Thermodynamic structure of a grass fire plume. International Journal of Wildland Fire 19, 895-902, https://doi.org/10.1071/WF09009.

Clements, C. B., and Coauthors, 2015: Fire weather conditions and fire-atmosphere interactions observed during low-intensity prescribed fires - RxCADRE 2012. International Journal of Wildland Fire, 25, 90-101, https://doi.org/10.1071/WF14173.

Cruz, M. G., Sullivan, A. L., Gould, J. S., Sims, N. C., Bannister, A. J., Hollis, J. J., \& Hurley, R. J., 2012: Anatomy of a catastrophic wildfire: The Black Saturday 
Kilmore East fire in Victoria, Australia. Forest Ecology and Management, 284, 269-285, https://doi.org/10.1016/j.foreco.2012.02.035.

Dempsey, Frank, 2013: Forest Fire Effects on Air Quality in Ontario: Evaluation of Several Recent Examples. Bull. Amer. Meteor. Soc., 1059-1064, https://doi.org/10.1175/BAMS-D-11-00202.

Dowdy, A. J., 2018: Climatological Variability of Fire Weather in Australia. . J. Appl. Meteor. Climatol. 57, 221-234, https://doi.org/10.1175/JAMC-D-17-0167.1.

Fromm, M., A. Tupper, D. Rosenfeld, R. Servranckx, R. McRae, 2006: Violent pyroconvective storm devastates Australia's capital and pollutes the stratosphere. Geophysical Research Letters. 33, https://doi:10.1029/2005GL025161.

Fromm, M.D., R.H.D. McRae, J. Sharples, G. P. III, 2012: Pyrocumulonimbus pair in Wollemi and Blue Mountains National Parks, 22 November 2006. Australian Meteorological and Oceanographic Journal. 62, https://doi.org/10.22499/2.6203.001.

Helmus, J.J. and S.M. Collis, 2016: The Python ARM Radar Toolkit (Py-ART), a Library for Working with Weather Radar Data in the Python Programming Language. Journal of Open Research Software, 4, 25, https://doi.org/10.5334/jors.119. 
Johnson, B. T., S. R. Osborne, J. M. Haywood, M. A. J. Harrison, 2008: Aircraft measurements of biomass burning aerosol over West Africa during DABEX. . $J$. Geophys. Res. Atmos., 113, 1-15, https://doi.org/10.1029/2007JD009451.

Jones, T. A., S. A. Christopher, and W. Petersen, 2009: Dual-polarization radar characteristics of an apartment fire. J. Atmos. Oceanic Technol., 26, 2257-2269, https://doi.org/10.1175/2009JTECHA1290.

Jones, T. A., and S. A. Christopher, 2009: Injection Heights of Biomass Burning Debris Estimated From WSR-88D Radar Observations. IEEE Transactions on Geoscience and Remote Sensing, 47, 2599-2605.

Jones, T. A., and S. A. Christopher, 2010: Satellite and radar remote sensing of southern plains grass fires: A case study. J. Appl. Meteor. Climatol. 49, 2133-2146, https://doi.org/10.1175/2010JAMC2472.

Koo, E., P. J. Pagni, D. R. Weise, J. P. Woycheese, 2010: Firebrands and spotting ignition in large-scale fires. International Journal of Wildland Fire, 19, 818-843, https://doi.org/10.1071/WF07119.

Lang, T. J., S. A. Rutledge, B. Dolan, P. Krehbiel, W. Rison, D. T. Lindsey, 2014: Lightning in Wildfire Smoke Plumes Observed in Colorado during Summer 2012. Mon. Wea. Rev., 142, 489-507, https://doi.org/10.1175/MWR-D-13-00184.1. 
Lareau, N. P., and C. B. Clements, 2016: Environmental controls on pyrocumulus and pyrocumulonimbus initiation and development. Atmos. Chem. and Phys., 16, 4005-4022.

Lareau, N. P., and C. B. Clements, 2017: The Mean and Turbulent Properties of a Wildfire Convective Plume. J. Appl. Meteor. Climatol., 2289-2299.

LaRoche, K. T. and T. J. Lang, 2017: Observations of Ash, Ice, and Lightning within Pyrocumulus Clouds Using Polarimetric NEXRAD Radars and the National Lightning Detection Network. Mon. Wea. Rev., 145, 4899-4910, https://doi.org/10.1175/MWR-D-17-0253.1

McCarthy, N., H. McGowan, A. Guyot, A. Dowdy, 2018: Mobile x-pol radar: A new tool for investigating pyroconvection and associated wildfire meteorology. Bulletin of the American Meteorological Society, 99, 1177-1195, https://doi.org/10.1175/BAMS-D-16-0118.1

McCarthy, N., A. Guyot, A. Dowdy, H, McGowan, 2019: Wildfire and Weather Radar: A Review. J. Geophys. Res. Atmos., 124, 266-286, https://doi.org/10.1029/2018JD029285.

McRae, R., J. J. Sharples, M. Fromm, 2015: Linking local wildfire dynamics to pyroCb development. Nat. Hazards Earth Syst. Sci., 15, 417-428, https://doi.org/10.5194/nhess-15-417-2015. 
Maesaka, T., K. Iwanami, M. Maki, 2012: Non-negative KDP Estimation by Monotone Increasing PHIDP Assumption below Melting Layer. The Seventh European Conference on Radar Meteorology and Hydrology.

Melnikov, V. M., D. S. Zrnić, R. M. Rabin, P. Zhang, 2008: Radar polarimetric signatures of fire plumes in Oklahoma. J. Geophys. Res., 35, L14815, https://doi.org/10.1029/2008GL034311.

Melnikov, V. M., D. S. Zrnić, R. M. Rabin, 2009: Polarimetric radar properties of smoke plumes: A model. J. Geophys. Res., 114, D21204, https://doi.org/10.1029/2009JD012647.

Price, O. E., B. Horsey, N. Jiang, 2016: Local and regional smoke impacts from prescribed fires. Nat. Hazards Earth Syst. Sci., 16, 2247-2257, https://doi.org/10.5194/nhess-16-2247-2016.

Prichard S.J., Larkin N.K., Ottmar R.D., French N.H.F., Brown T., Baker K., Clements C.B., Dickinson M., Hudak A., Kochanski A., Linn R., Liu Y., Potter B., Mell W.E., Tanzer D., Urbanski S., Watts A., 2019: The Fire and Smoke Model Evaluation Experiment - a plan for integrated, large fire-atmosphere field campaigns. Atmosphere, 10(2) 66.

ProSensing: Dual Frequency Scanning Cloud Radar (SACR). Accessed 1 April 2019, https://www.prosensing.com/crb-product/sacr/.

Rauber, R. M., and S. W. Nesbitt, 2018: Radar Meteorology: A First Course. 2018 John Wiley \& Sons Ltd., 461 pp. 
Reid, J. S., R. Koppmann, T. F. Eck, D. P. Eleuterio, 2005: A review of biomass burning emissions part II: intensive physical properties of biomass burning particles. Atmos. Chem. and Phys., 4, 5135-5200, https://doi.org/10.5194/acpd-4-51352004.

Rodriguez, Bruno, 2018: Airborne Doppler Radar Observations of PyroCu/Cb Plume Kinematics and Thermodynamics During the 2016 Pioneer Fire. Master's Thesis, San José State University, San José, CA, USA, 84 pp.

Schneebeli, M., J. Grazioli, A. Berne, 2014: Improved Estimation of the Specific Differential Phase Shift Using a Compilation of Kalman Filter Ensembles. IEEE Transactions on Geoscience and Remote Sensing, 52, 5137-5149, https://doi.org/10.1109/TGRS.2013.2287017.

U. S. Forest Service, 2019: Fire and Smoke Model Evaluation Experiment (FASMEE): Fishlake National Forest prescribed burn. United States Department of Agriculture, Accessed 6 April 2019, https://www.fs.usda.gov/rmrs/projects/fireand-smoke-model-evaluation-experiment-fasmee-fishlake-national-forestprescribed-burn.

Vulpiani, G., M. Montopoli, L. D. Passeri, A. G. Gioia, P. Giordano, F. S. Marzano, 2012: On the Use of Dual-Polarized C-Band Radar for Operational Rainfall Retrieval in Mountainous Areas. J. Appl. Meteor. Climatol. 51, 405-425, https://doi.org/10.1175/JAMC-D-10-05024.1. 
Zrnic, D., P. Zhang, V. Melnikov, D. Mirkovic, 2020: Of fire and smoke plumes, polarimetric radar characteristics. Atmos., 11(4), https://doi.org/10.3390/atmos11040363. 


\section{Appendix A}

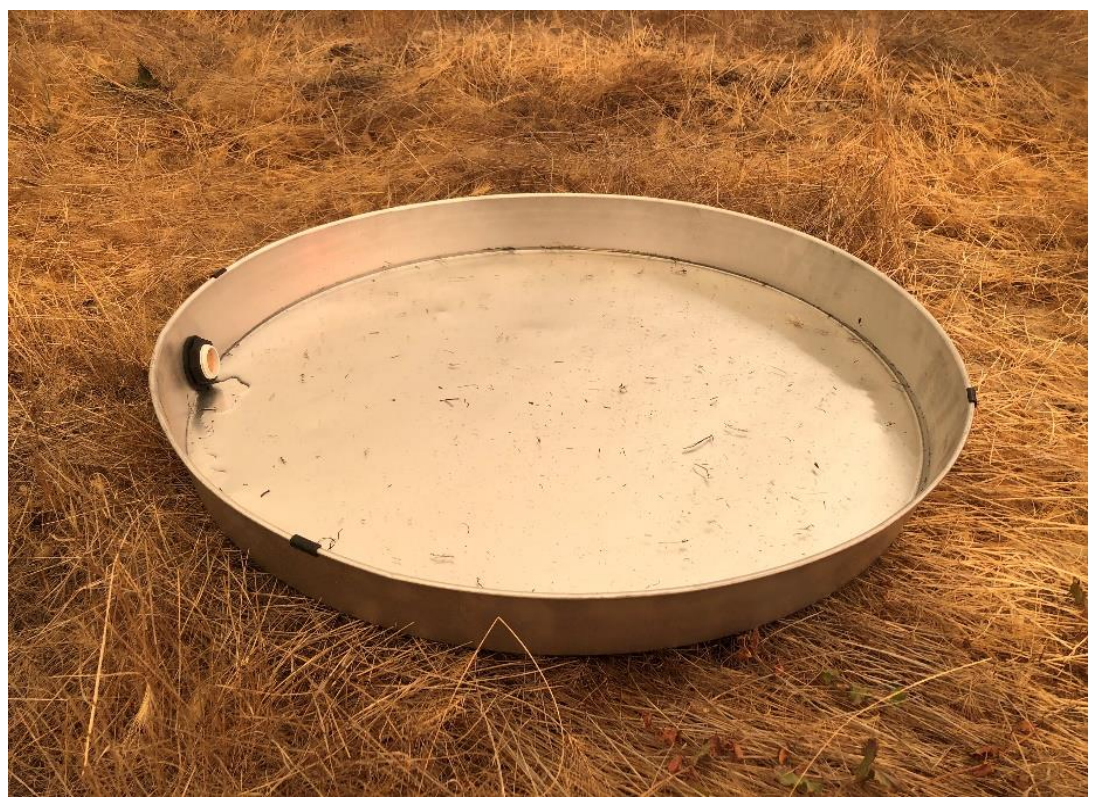

Fig. 14. Photo taken at Kincade D1 of ash and debris fallout at the radar site.

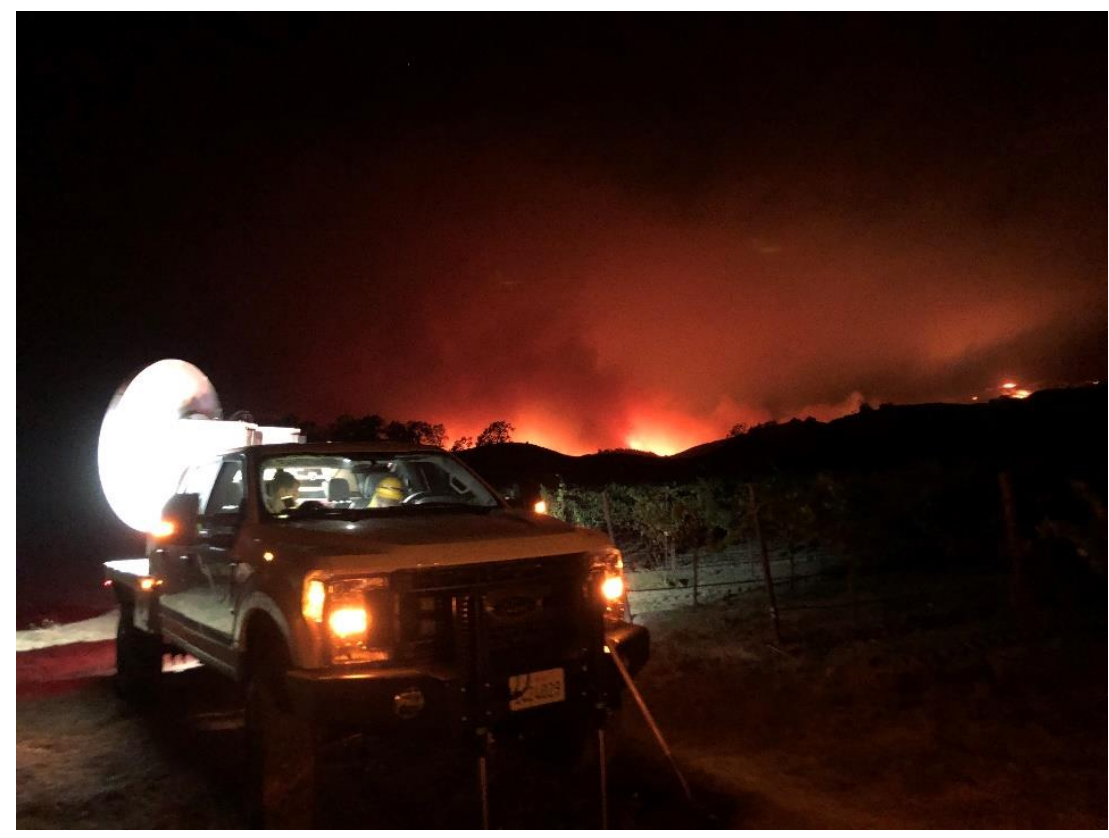

Fig. 15. Photo taken at Kincade D2 of KASPR unit and active fire. 


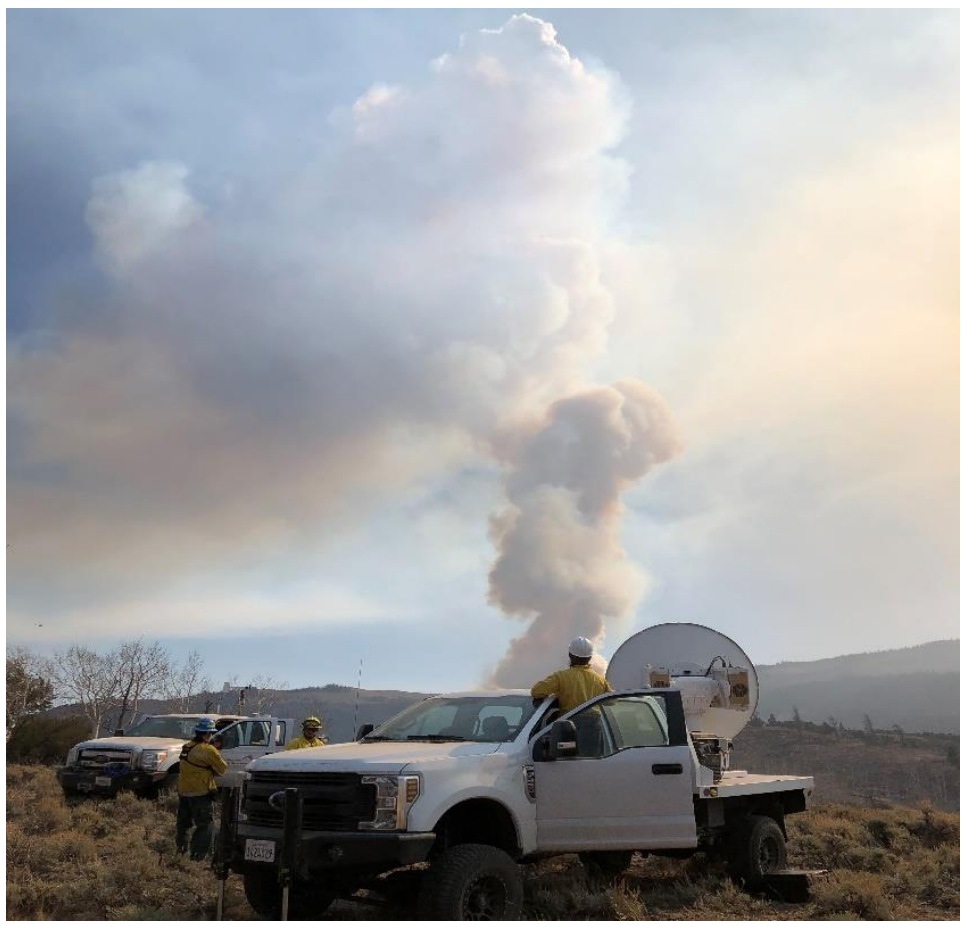

Fig. 16. Photo taken at the South Monroe prescribed fire of the radar unit at 1318 MST.

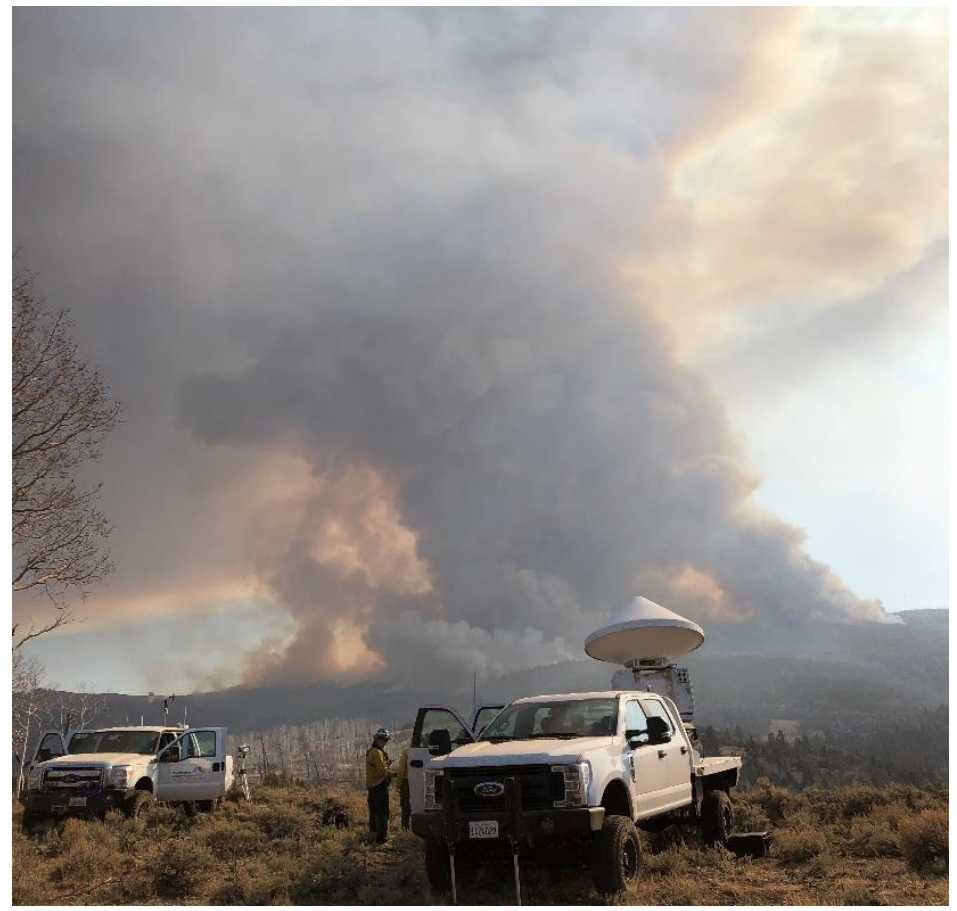

Fig. 17. Photo taken at the South Monroe prescribed burn at 1428 MST. 


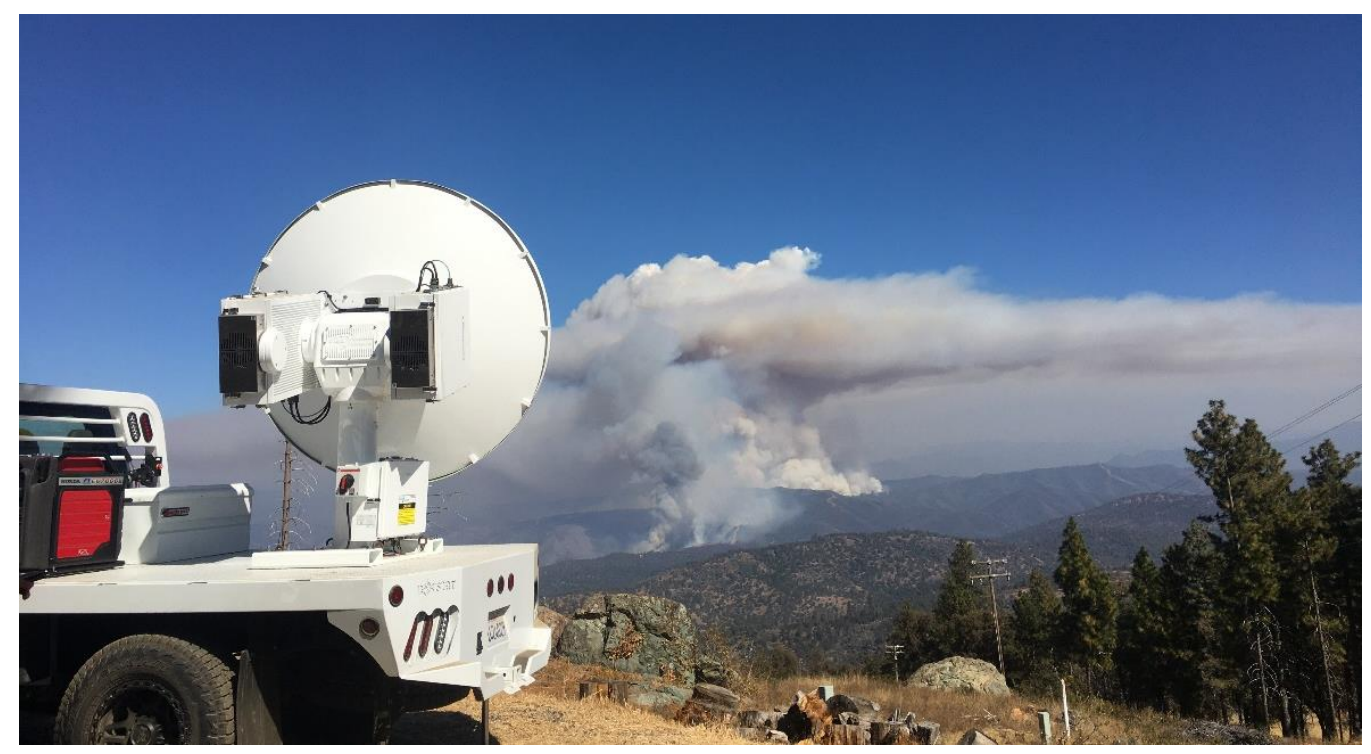

Fig. 18. Photo taken at the Briceburg wildfire showing the location and position of the radar unit. 